\title{
Reparative Myogenesis in Long-Term Denervated Skeletal Muscles of Adult Rats Results in a Reduction of the Satellite Cell Population
}

\author{
EDUARD I. DEDKOV, ${ }^{1 *}$ TATIANA Y. KOSTROMINOVA, ${ }^{1}$ \\ ANDREI B. BORISOV,$^{1}$ AND BRUCE M. CARLSON ${ }^{1,2}$ \\ ${ }^{1}$ Department of Cell and Developmental Biology, University of Michigan, \\ Ann Arbor, Michigan \\ ${ }^{2}$ Institute of Gerontology, University of Michigan, Ann Arbor, Michigan
}

\begin{abstract}
This study, conducted on 25-month denervated rat hindlimb muscles, was directed toward elucidating the basis for the poor regeneration that is observed in long-term denervated muscles. Despite a $\sim 97.6 \%$ loss in mean cross-sectional area of muscle fibers, the muscles retained their fascicular arrangement, with the fascicles containing $\sim 1.5$ times more fibers than age-matched control muscles. At least three distinct types of muscle fibers were observed: degenerating, persisting (original), and newly formed (regenerated) fibers. A majority of newly formed fibers did not appear to undergo complete maturation, and morphologically they resembled myotubes. Sites of former motor end-plates remained identifiable in persisting muscle fibers. Nuclear death was seen in all types of muscle fibers, especially in degenerating fibers. Nevertheless, the severely atrophic skeletal muscles continued to express developmentally and functionally important proteins, such as MyoD, myogenin, adult and embryonic subunits of the nicotinic acetylcholine receptor, and neural-cell adhesion molecule. Despite the prolonged period of denervation, slow and fast types of myosin were found in surviving muscle fibers. The number of satellite cells was significantly reduced in long-term denervated muscles, as compared with age-matched control muscles. In 25-month denervated muscle, satellite cells were only attached to persisting muscle fibers, but were never seen on newly formed fibers. Our data suggest that the absence of satellite cells in a population of immature newly formed muscle fibers that has arisen as a result of continuous reparative myogenesis may be a crucial, although not necessarily the only, factor underlying the poor regenerative ability of long-term denervated muscle. Anat Rec 263:139-154, 2001. ๑ 2001 Wiley-Liss, Inc.
\end{abstract}

Key words: prolonged denervation; skeletal muscle fibers; satellite cells; electron microscopy; immunohistochemistry; RT-PCR; Western-blot analysis; myogenin; MyoD; nAChR; N-CAM

Prolonged denervation causes multiple functional and morphological changes in skeletal muscle due to the absence of motor and trophic regulatory control by the nerve (Gutmann, 1962). The most prominent features of denervated skeletal muscles are the rapid atrophy of muscle fibers and a decrease in the number of both myonuclei and satellite cells (Anzil and Wernig, 1989; Borisov and Carlson, 2000; Gutmann and Zelená, 1962; Rodrigues and Schmalbruch, 1995; Schmalbruch and Lewis, 2000; Schmalbruch et al., 1991; Viguie et al., 1997). A major question that continues to be poorly understood is why, after several months of denervation, skeletal muscle loses the ability to become restored to a full structural and functional state even after nerve regeneration into the muscle (Carlson and Faulkner, 1988; Carlson et al., 1996; Fu and Gordon, 1995; Gulati, 1988,1990; Gutmann, 1948;

Grant sponsor: NIH; Grant number: PO1-AG10821.

*Correspondence to: Dr. Eduard I. Dedkov, M.D., Ph.D., Department of Cell and Developmental Biology, 4643 Medical Sciences II Building, University of Michigan, Ann Arbor, MI 48109. E-mail: ededkov@umich.edu

Received 2 August 2000; Accepted 8 February 2001 
Gutmann and Young, 1944; Irintchev et al., 1990). Among the possible explanations for the incomplete restoration of very long-term denervated muscle are a failure of regenerating nerves to reach all of the atrophic muscle fibers and establish mature muscle-nerve contacts (Fu and Gordon, 1995; Gutmann and Young, 1944; Irintchev et al., 1990) and/or a steady decline in the number of satellite cells (Rodrigues and Schmalbruch, 1995; Schmalbruch and Lewis, 2000; Viguie et al., 1997). However, there are observations that during muscle denervation, from several weeks to a few months, the regeneration of new fibers from satellite cells is often sufficient for maintaining a normal or even increased number of viable muscle fibers (Bittner et al., 1995; Mussini et al., 1987; Schmalbruch et al., 1991; Schmalbruch and Lewis, 2000; Viguie et al., 1997).

Development of a number of new methods during the last several years has allowed better evaluation of the changes in muscle fibers under normal and pathological conditions at both molecular and structural levels. For example, it has been shown that denervation of skeletal muscle fibers results in reactivation of the myogenic basic helix-loop-helix transcription factors, $\mathrm{MyoD}$ and myogenin (Adams et al., 1995; Eftimie et al., 1991; Merlie et al., 1994; Weis, 1994), as well as elevation of the expression levels of some embryonic muscle-specific proteins, such as N-CAM (Covault and Sanes, 1985, 1986; Moore and Walsh, 1986; Sanes et al., 1986; Walsh and Moore, 1985) and the $\gamma$-subunit of nAChR (Adams et al., 1995; Witzemann et al., 1987).

The current study is a continuation of research that has been done in our laboratory (Lu et al., 1997; Viguie et al., 1997) designed to elucidate the status of skeletal muscles after long-term denervation. The specific question in this study was whether the changes in extremely long-term denervated skeletal muscles represent only a steady deterioration of muscle tissue or if concurrent active cellular compensatory processes accompany them.

\section{MATERIALS AND METHODS Animals and Denervation}

This study was conducted on 4-month-old male rats of the WI/HicksCar strain. After ether anesthesia, the right sciatic nerve was tightly ligated with silk in two places and the nerve was cut between the sutures. Both proximal and distal nerve stumps were implanted into muscular tissue as far away from each other as possible. This method is routinely used for long-term denervation of the hind limb (Viguie et al., 1997). All operations and subsequent animal care were carried out in accordance with the guidelines of the Unit for Laboratory Animal Medicine at the University of Michigan. After operations, the rats were treated with oral terramycin for 5 days. At 29 months of age the extensor digitorum longus (EDL), tibialis anterior (TA), and gastrocnemius muscles were removed from both denervated and normal contralateral legs from each of four rats, and the animals were euthanized by an overdose of anesthetic. Age-matched muscles from both non-operated rats (two rats) and contralateral legs of denervated animals (four rats), along with normal and 1-month denervated muscles from three 5-month-old rats, served as controls.

\section{Light and Transmission Electron Microscopy}

Small pieces of EDL muscles from the midbelly area were fixed with a mixture of $4 \%$ paraformaldehyde and $2.5 \%$ glutaraldehyde in $0.1 \mathrm{M}$ phosphate buffer saline (PBS) at $\mathrm{pH}$ 7.4, washed in PBS and post-fixed in 1\% $\mathrm{OsO}_{4}$. Samples were further dehydrated in a graded series of ethanol and absolute acetone and then embedded in mixture of Epon/Araldite using an Eponate 12 $2^{\mathrm{TM}}$-Araldite 502 Kit (Ted Pella, Inc., Redding, CA). Transverse semithin and ultrathin sections were cut with an ultramicrotome. The 1.0- $\mu \mathrm{m}$ sections were mounted on glass slides and stained with toluidine blue for general observation. Ultrathin sections were collected on formvar-coated slotted grids, stained with uranyl acetate and lead citrate, and examined with a Philips CM-100 transmission electron microscope.

\section{Quantitative and Morphometric Analysis}

Quantitative analyses. Forty-eight and 90 muscle fascicles, from control and denervated EDL muscles, respectively, were examined on ultrathin sections by transmission electron microscopy. Before any calculation was performed, the phenotype of each cell in the fascicles was recognized under the high magnification. The criteria used to identify the muscle fibers were the presence of basal lamina and myofibrils. The numbers of muscle fiber profiles, myonuclei and satellite cell nuclei on cross-sections of muscle fascicles were recorded as follows: 1.) the distribution of fascicles according to the number of muscle fibers per fascicle was laid out in histograms; 2 .) the mean number of myonuclei per fascicle plotted against the mean number of muscle fibers in the same fascicle was presented as a histogram; 3.) the mean numbers of muscle fibers and myonuclei per fascicle were also calculated; 4 .) the myonuclei/muscle fiber $(\mathrm{Mn} / \mathrm{F})$ ratio was calculated; 5.) satellite cell numbers were expressed in two ways: first, as a percentage of the total number of nuclei counted beneath the basement membranes in cross-sections, and second, as ratio of the total number of satellite cells to the total number of muscle fibers calculated in all cross-sectioned fascicles that were examined.

Morphometric analyses. Measurements of cross-sectional area (CSA) of the muscle fibers were made on transverse semi-thin sections from the same samples that were used for electron microscopy. Images of the tissues were captured from the sections onto a DELL Precision 410 computer by using a Zeiss Axiophot-2 Universal Microscope with a Zeiss Axiocam digital camera (Carl Zeiss Inc., Germany). The images were converted to grayscale on a Power Macintosh 7300/200 computer by using NIH Image 1.62. The circumferences of muscle fibers were electronically traced by using an ArtPad II and a graphics tablet with an Erasing UltraPen, and the CSAs were calculated in square micrometers $\left(\mathrm{mm}^{2}\right)$ with the help of NIH Image 1.62. The distribution of muscle fibers according to CSA in control and denervated EDL muscles was laid out in histograms.

\section{Immunohistochemistry}

Technique. TA muscles were fixed in freshly prepared $2 \%$ paraformaldehyde in PBS at $4^{\circ} \mathrm{C}$ and were then transversely cut in the midbelly area. The samples were washed overnight in PBS, cryoprotected by immersion in a 
graded sucrose series, placed in specimen molds containing TBS/Tissue Freezing Medium (Triangle Biomedical Sciences, Durham, NC), and quickly frozen by immersing the molds in isopentane that had been cooled by dry ice. Transverse 9.0- $\mu \mathrm{m}$ sections from the midbelly area of each muscle were cut with a cryostat, mounted on warm glass slides, and placed in a freezer at $-20^{\circ} \mathrm{C}$ for storage. Before staining, the sections were washed in double distilled water and fixed in cooled $100 \%$ methanol. The slides were allowed to air-dry and then the sections were rehydrated in PBS. Double labeling with a mixture of different primary antibodies was carried out at room temperature for $3 \mathrm{hr}$. After incubation the sections were washed in PBS and stained with a mixture of the secondary antibodies at room temperature for $45 \mathrm{~min}$. After staining with secondary antibodies, the sections were rinsed in PBS, mounted in VECTASHIELD mounting medium for fluorescence with DAPI (Vector Laboratories, Burlingame, CA), and coverslipped. Observation and photography of the sections were made with a Zeiss Axiophot-2 Universal Microscope (Carl Zeiss Inc., Germany).

Antibodies. Primary antibodies used for the staining were: (1) mouse monoclonal anti-rabbit skeletal myosin (Fast), clone MY-32 (Sigma, St. Louis, MO); (2) mouse monoclonal anti-human skeletal myosin (Slow), clone NOQ7.5.4D, (Chemicon International Inc., Temecula, CA); (3) mouse monoclonal anti-rat myogenin, clone F5D (Developmental Studies Hybridoma Bank (DSHB), The University of Iowa, Iowa City, IA); (4) mouse monoclonal anti-MyoD1, clone 5.8A (NeoMarkers Inc., Union City, CA); (5) mouse monoclonal anti-rat laminin B2, clone D18 (DSHB, The University of Iowa, Iowa City, IA); (6) rabbit polyclonal anti-mouse laminin (Sigma, St. Louis, MO); and (7) rabbit polyclonal anti-chicken NCAM (Chemicon International Inc., Temecula, CA).

FITC- or Cy3-conjugated goat anti-mouse or goat antirabbit IgG (Jackson ImmunoResearch laboratories, Inc.) were used for visualization of primary antibodies.

\section{Western Blot Analysis}

The gastrocnemius muscles were frozen in liquid nitrogen, pulverized, and homogenized in a solution containing 20 mM Tris-HCl ( $\mathrm{pH}$ 6.8), 4\% (wt/vol.) sodium dodecyl sulphate (SDS), $1 \mathrm{mM}$ of phenylmethylsulfonyl fluoride (PMSF), and $1 \mu \mathrm{m}$ each of Leupeptin and Pepstatin A. Protein concentrations were determined using the BioRad detergent compatible protein assay (Hercules, CA). Equal amounts of protein from each sample $(50 \mu \mathrm{g}$ per lane) were mixed with loading buffer, subjected to SDSpolyacrylamide gel electrophoresis $(7.5 \%)$, and transferred electrophoretically to Immobilon-P membranes (Millipore, Bedford, MA). Gels with identical samples were stained with Coomassie brilliant blue and used as an additional control of equilibration of protein loading. After transfer, the Immobilon-P membranes were blocked in Blotto buffer containing 5\% dry milk in PBS-0.05\% Tween 20 (PBST) and then incubated overnight at $4^{\circ} \mathrm{C}$ with mouse monoclonal antibodies against myogenin (clone F5D, DSHB, The University of Iowa, Iowa City, IA), $\alpha$-subunit of the nAChR (Chemicon International Inc., Temecula, CA) or NCAM (clone AG1, DSHB, The University of Iowa, Iowa City, IA). Immunodetection was done using peroxidaseconjugated goat anti-mouse antibody (Jackson ImmunoResearch Lab., West Grove, PA) with subsequent chemiluminescence (ECL, Amersham Pharmacia Biotech, Piscataway, NJ).

\section{Reverse Transcriptase Polymerase Chain Reaction (RT-PCR)}

Total RNA was isolated from gastrocnemius muscles by homogenization in TRIzol (GIBCO BRL, Grand Island, NY) followed by the single step purification method as described by the manufacturer's protocol. The RNA concentration was estimated using a spectrophotometer and an equal amount of total RNA (5 $\mu \mathrm{g}$ per reaction) was reverse-transcribed to synthesize single-stranded cDNA using the SuperScript ${ }^{\mathrm{TM}}$ Preamplification System (GIBCO BRL, Grand Island, NY) according to the manufacturer's protocol.

PCR amplification was performed using the following conditions: $2 \mu \mathrm{L}$ of single-stranded cDNA from a reverse transcription reaction was amplified at $95^{\circ} \mathrm{C}$ for 5 min for one cycle followed by $95^{\circ} \mathrm{C}$ for $1 \mathrm{~min}, 60^{\circ} \mathrm{C}$ for $1 \mathrm{~min}$, and $72^{\circ} \mathrm{C}$ for $1 \mathrm{~min}$ for 30 cycles. The PCR products were run out in a $1 \%$ agarose gel and visualized by Ethidium Bromide staining. The PCR reactions were in the linear range with respect to input of the RNA.

Primers used for detecting muscle-specific transcripts were: 1.) MyoD, 5'-AGG CTC TGC TGC GCG ACC A-3' forward and 5' -TGC AGC CAA CCT CTC AGA GCA CC-3' reverse, with a 489-bp PCR product (Kraus and Pette, 1997); 2.) myogenin, 5'-AGT GAA TGC AAC TCC CAC AGC GCC T-3' forward and 5' -TGG CTT GTG GCA GCC CAG GG-3' reverse, with a 328-bp PCR product (Kraus and Pette, 1997); 3.) $\alpha$-subunit of the nAChR, $5^{\prime}$-CGT CTG GTG GCA AAG CT-3' forward and 5'-CCG CTC TCC ATG AAG TT-3' reverse, with a 505-bp PCR product (Horton et al., 1993); 4.) $\epsilon$-subunit of the nAChR, 5'-GAG GAC ACT GTC ACC AT-3' forward and 5'-CAC GAT GAC GCA ATT CAT-3' reverse, with a 840-bp PCR product (Horton et al., 1993); and 5.) $\gamma$-subunit of the nAChR, 5'-CAT CAG CAA GTA CCT GAC-3' forward and 5'-TGC TTC AGG CTG CCA CA-3' reverse, with a 393-bp PCR product (Horton et al., 1993).

To control for equal amounts of input, primers specific to glyceraldehyde 3-phosphate dehydrogenase (GAPDH) and muscle creatine kinase (MCK) were used: (1) GAPDH, 5'-GGT GAA GGT CGG TCT CAA CGG A-3' forward and 5' -CCA CAG ATG CCA AAG TTG TCA TGG A-3' reverse, with a 505-bp PCR product; (2) MCK, 5'-TTC ATC ATG ACG GGC AGA GTG-3' forward and 5'-AGG TGA CAC GGG CTT GTC AAA CAG-3' reverse, with 398-bp PCR product.

\section{Statistical Analysis}

Quantitative data were analyzed with a two-way analysis of variance (ANOVA) followed by the Student's $t$-test (unpaired sample). The values are expressed as means \pm SEM. The level of significance between control and denervation was set at $* P=0.05, * * P=0.01, * * * P=0.001$.

\section{RESULTS \\ General Structure and Muscle-Specific Gene Expression in Denervated Muscles}

Our study has shown that after 25 months of sciatic nerve transection, the denervated fibers in EDL muscles represent only $\sim 2.4 \%$ cross-sectional area (CSA) of control 
TABLE 1. Quantitative and morphometric analyses of control and 25-month denervated EDL muscles of 29-month-old rats ${ }^{\dagger}$

\begin{tabular}{|c|c|c|c|c|c|c|}
\hline & \multirow{2}{*}{$\begin{array}{l}\text { CSA of muscle } \\
\text { fibers in } \mu \mathrm{m}^{2}\end{array}$} & \multirow{2}{*}{$\begin{array}{l}\text { Number of } \\
\text { muscle fibers } \\
\text { per fascicle }\end{array}$} & \multirow{2}{*}{$\begin{array}{l}\text { Number of } \\
\text { myonuclei } \\
\text { per fascicle }\end{array}$} & \multirow[b]{2}{*}{$\mathrm{Mn} / \mathrm{F}$ ratio } & \multicolumn{2}{|c|}{ Satellite cells (SC) } \\
\hline & & & & & $\mathrm{SCn} / \mathrm{Mn}+\mathrm{SCn}$ & $\mathrm{SCn} / \mathrm{F}$ \\
\hline 0011 & $2104.5 \pm 115.7$ & $18.6 \pm 0.1$ & $19.7 \pm 1.3$ & $1.06 \pm 0.06$ & $1.42 \pm 0.38 \%$ & $1.5 \pm 0.3 \%$ \\
\hline Denervation & $50.6 \pm 4.4^{* *}$ & $28.5 \pm 0.8^{* * *}$ & $12.9 \pm 0.9 *$ & $0.45 \pm 0.02^{* * *}$ & $0.51 \pm 0.03 \% *$ & $0.23 \pm 0.01 \%$ ** \\
\hline
\end{tabular}

Control, data were collected on 48 fascicles from 4 control EDL muscles of 29-month-old rats. Denervation, data were collected on 90 fascicles from four 25-month denervated EDL muscles of 29-month-old rats. CSA, cross-sectional area; F, total number of muscle fiber profiles in examined fascicles; Mn, total number of myonuclei in examined fascicles; SCn, number of satellite cell nuclei in examined fascicles. Values are mean \pm SEM. The mean for a 25-month denervated EDL muscle is different from control level: $* P \leq 0.05, * * P \leq 0.01, * * * P \leq 0.001$ (unpaired Student's $t$-test).

fibers (Table 1). In spite of such dramatic atrophy, the muscle fibers in denervated EDL muscles preserve their characteristic fascicular organization (Fig. 1A). Furthermore, the fascicles in long-term denervated EDL muscles maintain variability in size similar to those in innervated muscles (Fig. 2), but on average they contain almost 1.5 times more muscle fiber profiles than do fascicles of agematched control EDL muscles (Table 1). Muscle fibers in denervated fascicles continue to maintain heterogeneity in size (Fig. 1B), and the shape of distribution of their CSA is similar to that of control muscles (Fig. 3). In spite of a significant degree of atrophy, a majority of the surviving fibers show the presence of thin and thick myofilaments organized in sarcomere-like structures with electrondense areas resembling Z-lines. However, abnormalities in the arrangement of myofibrils, which are sometimes oriented at different angles to one another, have been systematically observed (Fig. 1D). Although the entire population of severely atrophic muscle fibers, in general, has very similar structural alterations, at least three distinct types of muscle fibers were found, based on conspicuous morphological features: degenerating, persisting (original), and newly formed (regenerated) fibers. Unfortunately, in a high number of the cases, when the crosssectioned fiber profiles were very small and non-nucleated, distinguishing between the types of muscle fibers was almost impossible (Fig.1G). We describe below the most common structural characteristics for each stated type of fiber. A prominent characteristic of degenerating muscle fibers is multiple figures of nuclear death (Fig. 1E). The principal features of persisting (original) muscle fibers are the presence of either intact peripheral myonuclei (Fig. 1F) or a site of a former motor end-plate (Fig. 4B-D). One of the controversial morphological appearances that has been found in a majority of the persisting muscle fibers of 25-month denervated EDL muscle is the absence of a convoluted basal lamina, whereas this is an undoubted characteristic of the denervated muscle fibers during the first months of atrophy. The newly formed (regenerated) muscle fibers are characterized by a centrally located nucleus (Fig. 1C, F, and H). Additionally, there are some differences among newly formed muscle fibers: some correspond to immature myotube-like structures, sometimes enveloped by a notably folded basal lamina (Fig. 1C), whereas others have a more developed morphology judging from the organized myofibrils in their cytoplasm (Fig. 1F, H). The differences observed in the structural features, such as amount of cytoplasm, development of the contractile apparatus, and status of the basal lamina, allow us to hypothesize that the population of newly formed muscle fibers in 25-month denervated EDL muscles is represented by fibers having different stages of maturation.

In spite of the fact that long-term denervated EDL muscles had a $\sim 1.5$ times higher number of muscle fibers per fascicle than age-matched control muscles, only $\sim 45 \%$ of their profiles were nucleated (Table 1). Plotting the mean number of myonuclei against the mean number of muscle fibers in the same fascicles of 25-month denervated EDL muscle showed that the decrease in number of the myonuclei was homogeneous and less dependent on the fascicle size (Fig. 5B). The low number of myonuclei might be explained by their systematic elimination within the whole population of muscle fibers and not only in degenerating muscle fibers. Occasionally observed figures of nuclear death in persisting as well as in newly formed muscle fibers support this observation (Fig. 6). Moreover, some of the persisting muscle fibers displayed intact nuclei closely located with figures of myonuclear death (Fig. 6B).

Immunolabeling of 25-month denervated EDL and TA muscles for fast- and slow-type myosin expression has shown that the differentiation of both Type II (fast) and

Fig. 1. Photomicrographs of 25-month denervated EDL muscle showing structural changes in the muscle fibers. A: The fascicular organization of muscle fibers in long-term denervated EDL muscle. Semi-thin section stained with toluidine blue. Arrowheads show a representative muscle fascicle. Scale bar $=25 \mu \mathrm{m}$. B: The muscle fibers in denervated fascicles have different degrees of atrophy. The large muscle fiber (asterisk) is co-localized with very small muscle fibers (arrows). Scale bar $=5 \mu \mathrm{m}$. C: Extremely small muscle fiber with centrally located nucleus is enveloped by the notably folded basal lamina (arrowheads). Scale bar $=1 \mu \mathrm{m}$. D: Cross-section of denervated muscle fiber showing myofibrils oriented at different angles to one another. Longitudinal projections of Z-line materials within the sarcomere-like structures are adjacent to transverse sections of myofibrils (arrows). Scale bar $=1 \mu \mathrm{m}$. E: Nuclear death is seen in a muscle fiber. The arrowheads show a pyknotic nucleus in a late stage of degeneration, whereas the other two nuclei (asterisks) display the earliest stages of nuclear degradation. Note a lamellar structure in the cytoplasm associated with the pyknotic myonucleus (arrows). Scale bar $=1 \mu \mathrm{m}$. F: Intact peripheral myonuclei are characteristic of persisting fiber (asterisk), whereas a single centrally located nucleus (arrow shows a small part of a nucleus) is a distinct feature of a regenerated muscle fiber. Scale bar $=2 \mu \mathrm{m}$. G: Very small non-nucleated segment of a muscle fiber is surrounded by a folded basal lamina (arrows). Note the well-arranged myofibrils in the cytoplasm (asterisk). Scale bar $=1 \mu \mathrm{m}$. H: Centrally located nucleus along with developed myofibrils in the cytoplasm (asterisk) confirms the progressively mature status of a newly formed myotube-like fiber. Scale bar = $1 \mu \mathrm{m}$. 

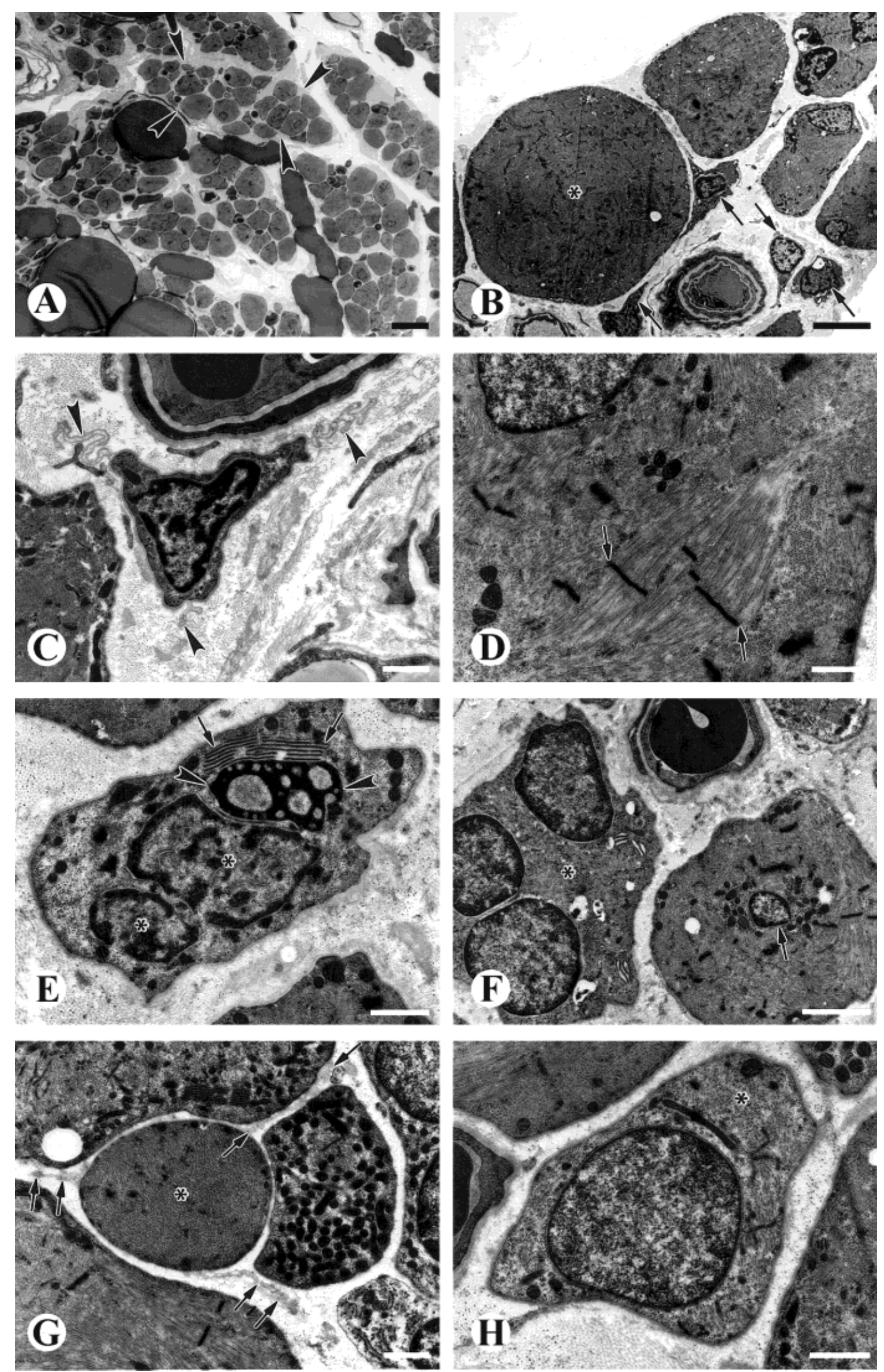

Figure 1. 


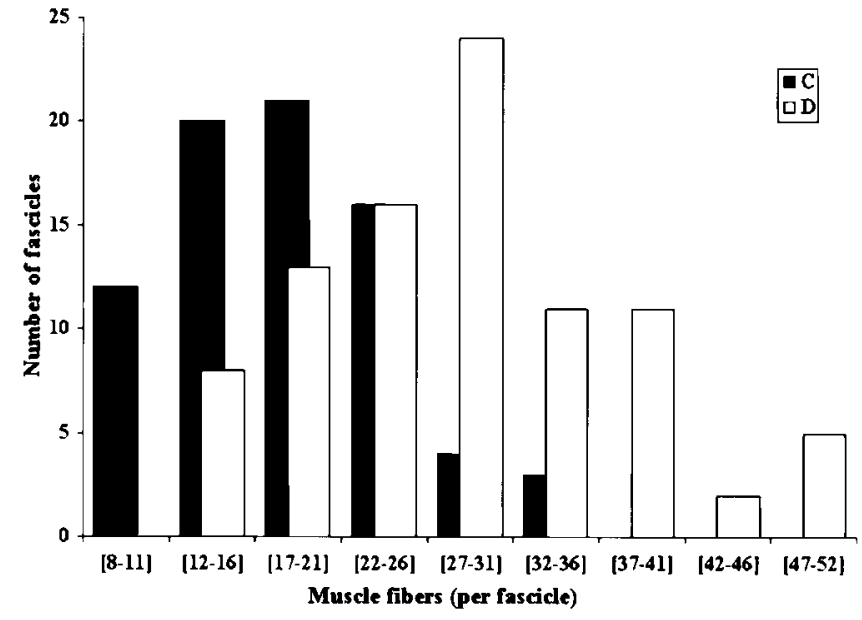

Fig. 2. Frequency distribution of muscle fascicles according to the number of muscle fibers per fascicle in control (C) and in 25-month denervated (D) EDL muscles of 29-month-old rats.

Type I (slow) fibers still remains. Nevertheless, after prolonged denervation a majority of muscle fibers express the fast-type myosin independently of fiber size, whereas only a few slow-type fibers were found (Fig. 7A-D). Staining with an antibody against fast-type or slow-type myosin has shown that contrary to control 29-month-old TA muscles, which had slow fiber-type grouping (Fig. $7 \mathrm{~F}, \mathrm{H}$ ), the fascicles in 25-month denervated TA muscles were characterized by almost pure populations of fast-type fibers (Fig. 7E, G).

The RT-PCR and Western-blot analyses of denervated gastrocnemius muscles indicated that after an extremely prolonged period of the absence of both motor function and trophic nerve influence, the viable muscle fibers were still able to express several functionally important musclespecific proteins at both the RNA and/or protein levels. Expression of the myogenic transcription regulatory factors (MyoD and myogenin), adult $\alpha-, \epsilon-$ and embryonic $\gamma$-subunits of the nicotinic acetylcholine receptor (nAChR) and distinct isoforms of neural-cell adhesion molecule (NCAM) was present in long-term denervated gastrocnemius muscles (Fig. 8).

Immunocytochemical study of 25-month denervated TA muscles has shown that both $\mathrm{MyoD}$ and myogenin proteins are present in nuclei of surviving muscle fibers (Fig. 9). It should be noted that MyoD-positive myonuclei are more abundant than myogenin-positive myonuclei. MyoD specific staining is observed in some of the nuclei of persisting muscle fibers, as well as in the nuclei of newly formed fibers (Fig. 9A, B), whereas myogenin specific labeling is observed exclusively in the centrally located nuclei of the regenerated muscle fibers (Fig. 9C, D).

$\mathrm{N}$-CAM protein in long-term denervated TA muscles is markedly expressed in the areas of attachment between persisting muscle fibers and associated structures resembling satellite cells and myotubes (Fig. 10A-D). However, on some rare occasions intense N-CAM labeling was also detected on the surface of persisting and newly formed muscle fibers in the absence of cell-to-cell contact (Fig. $10 \mathrm{E}-\mathrm{H})$.
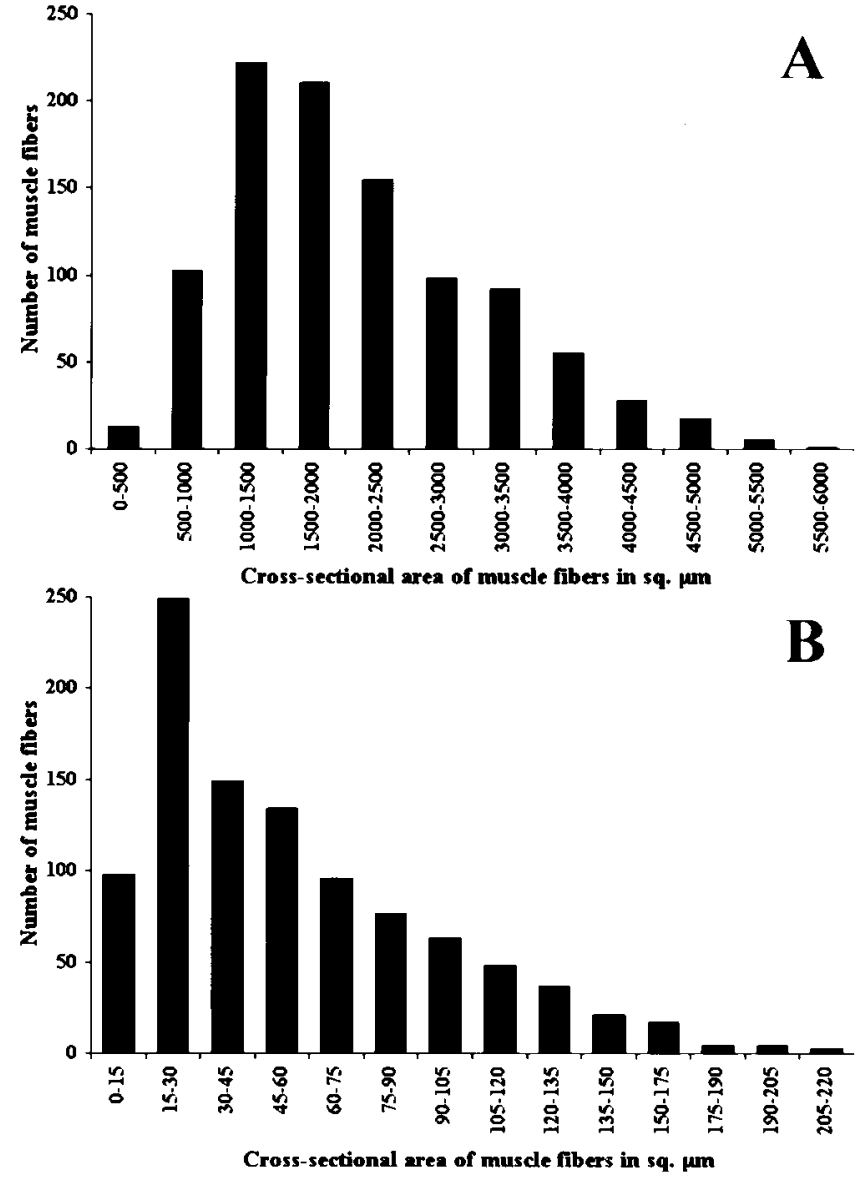

Fig. 3. Frequency distribution of muscle fibers according to their cross-sectional areas in control (A) and in 25-month denervated (B) EDL muscles of 29-month-old rats.

\section{Satellite Cells and Reparative Myogenesis}

Satellite cells showing the morphological appearance of activated forms, such as an increased amount of cytoplasm, extended cell processes, and de novo-formed basal lamina, are seen in 25-month denervated EDL muscles (Fig. 11). Compared to age-matched control muscles, the estimated number of satellite cells surviving in long-term denervated EDL muscles of 29-month-old rats was very low, and varied depending on the method of calculation that was used (Table 1). At the ultrastructural level, we observed that satellite cells were always attached to persisting muscle fibers (Fig. 11A) and we have never seen them associated with immature newly formed muscle fibers. On some of the transverse sections, activated satellite cells and/or immature myotube-like structures are located in shallow groove-like channels on the surface of persisting muscle fibers, and the gap separating them was filled with basal lamina material (Fig. 11C). It must also be noted that some of the satellite cells show the presence of centrioles in the cytoplasm (Fig. 11A, B). Frequently, activated satellite cells form cytoplasmic processes, which extend long distances and sometimes surround the atrophic persisting muscle fibers (Fig. 11D, E). It is well known that the final stage of satellite cell activation and 

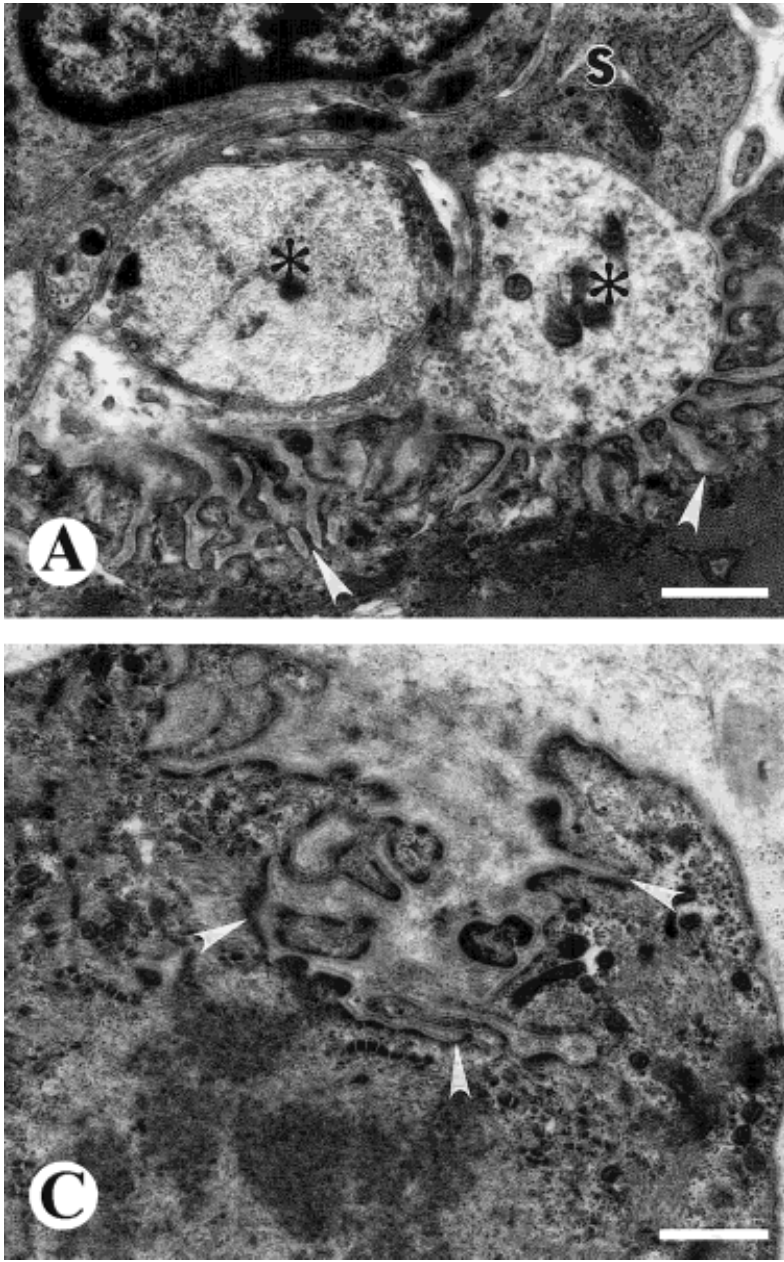

Fig. 4. Electron micrographs showing the motor end-plate areas in control 29-month-old and in 25-month-old denervated EDL muscles. A: Neuromuscular junction in a 29-month-old control EDL muscle. Nerve terminals (asterisks). Schwann cell (s). Synaptic folds (arrowheads).

myoblast growth is the formation of myotubes, which fuse to form new muscle fibers. In several cases, we observed a few separate myotubes that displayed different stages of differentiation and were surrounded by a common basal lamina (Fig. 11F).

\section{DISCUSSION}

Very long-term denervated skeletal muscles present a complex picture, consisting of muscle fiber atrophy, death, and regeneration, all of which must also be evaluated in the context of simultaneous aging changes. In our experiment, the hindlimbs of the rats were denervated at 4 months of age, at which time the rats had already completed their major growth phase. Denervation at earlier ages, especially during the immediate postnatal period, involves additional variables, including death of the severed motor neurons and less stability of the muscle fibers themselves (Schmalbruch, 1987, 1988, 1990; Soileau et al., 1987; Trachtenberg, 1998). Therefore, our experiment was designed to avoid disturbing the skeletal muscles during a period of postnatal instability.
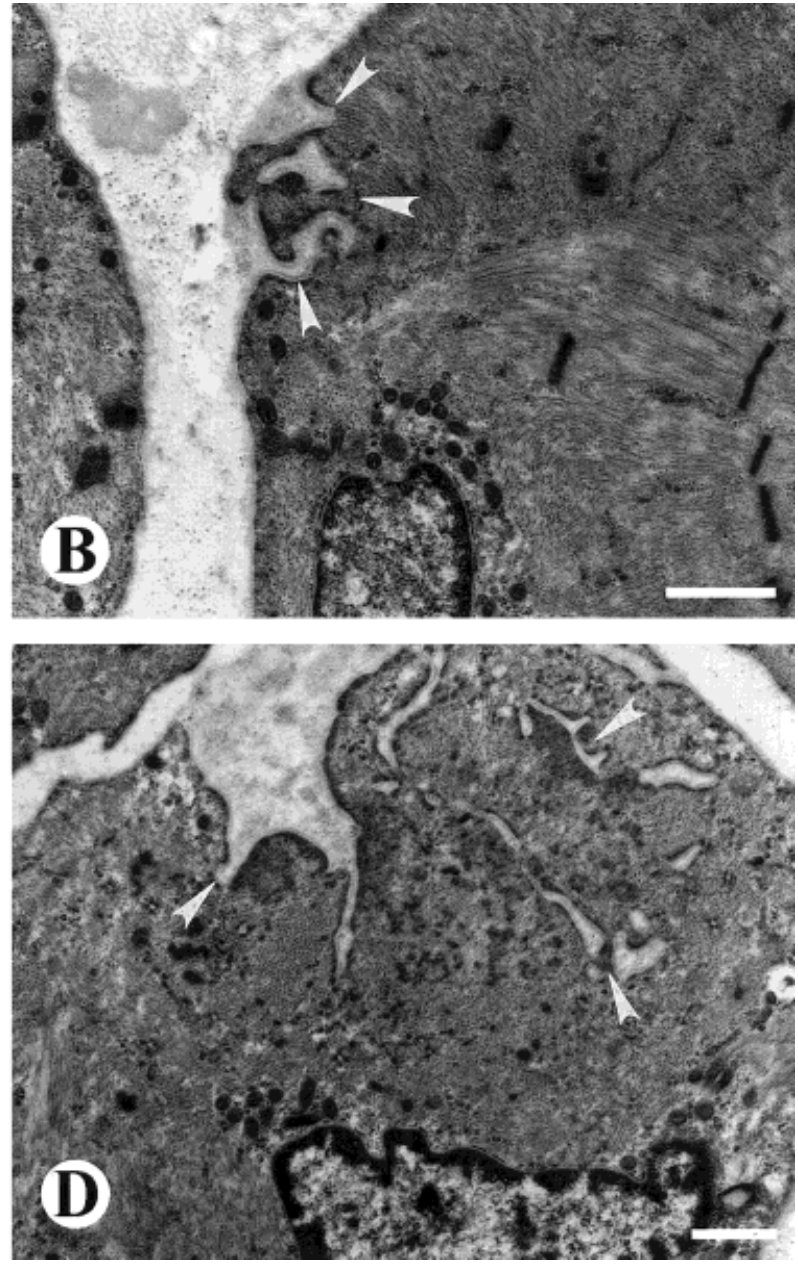

Scale bar $=1 \mu \mathrm{m}$. B-D: Sites of former motor end-plates on the surface of atrophied muscle fibers in 25-month denervated EDL muscles. Note the irregular and aberrant character of the synaptic folds (arrowheads) compared to the normal neuromuscular junction in A. Scale bar $=1 \mu \mathrm{m}$.

Despite a prolonged period of denervation, the fascicular organization of the EDL muscle was remarkably well preserved. A major change consisted of an increased number of muscle fibers per fascicle over the control level (Table 1). Previous studies have shown that increased numbers of muscle fibers in atrophic adult EDL muscle of rats could be seen after several months of denervation (Schmalbruch, 2000; Viguie et al., 1997). Our findings represent evidence that even after more than a 2 -year period of denervation, the EDL muscles continue to have an elevated number of muscle fibers arranged in fascicles. From our study, the mechanism underlying this change could not be definitively determined, but in view of the morphological and molecular results presented here, we suggest that the formation of new muscle fibers in extremely long-term denervated muscles undoubtedly takes place. In support of our idea, several studies have shown that myotube-like fibers begin to appear in the soleus and EDL muscles of adult rodents a few weeks after denervation and continue to be observed for several months in a post-denervation period (Lu et al., 1997; Mussini et al. 

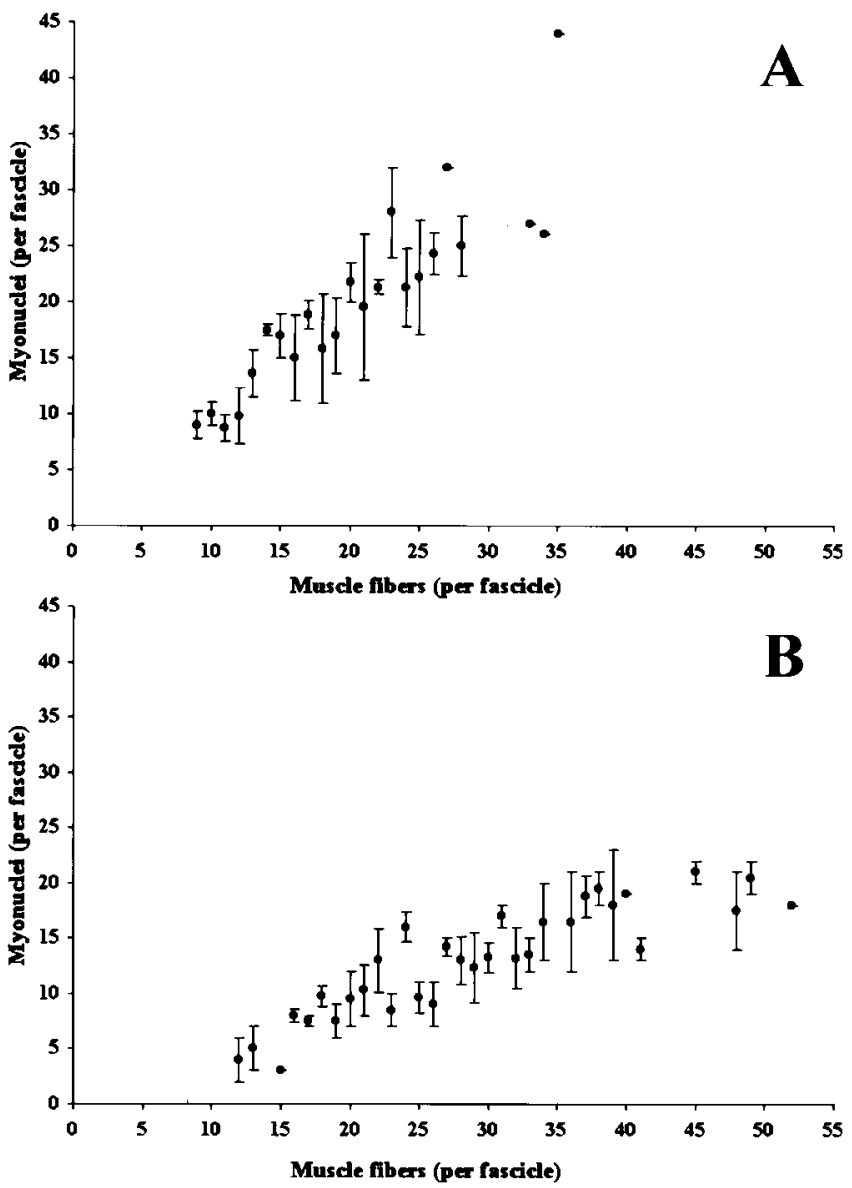

Fig. 5. Mean number of myonuclei per fascicle is plotted against the mean number of muscle fibers in the same fascicle in control $(\mathbf{A})$ and in 25-month denervated (B) EDL muscles of 29-month-old rats. Note that the decrease in the number of myonuclei in long-term denervated muscles is less dependent on fascicle size.

1987; Rodrigues and Schmalbruch, 1995; Schmalbruch et al., 1991). Schmalbruch et al. (1991) proposed that the formation of myotubes in denervated skeletal muscles is an apparent sign of concurrent reparative myogenesis that takes place after the loss of original muscle fibers. This process represents a sequence of numerous repeated cycles of necrosis and regeneration occurring in denervated muscles.

The degree of muscle fiber atrophy found in our study was extreme and presented a 40 -fold decrease from a control value in mean of fiber CSA (Table 1). According to morphometric evaluation, the fiber CSA of 25-month denervated EDL muscles is only $\sim 2.4 \%$ of that of control muscles. Our results are consistent with data showing that 6-10 months after denervation the mean fiber CSA or the mean fiber cytoplasmic volume of the EDL as well as the soleus muscles is only 2-3\% of control levels (Schmalbruch et al., 1991; Viguie et al., 1997). Based on our findings and data from other authors, it seems that after 6-7 months of denervation, fiber size in skeletal muscles of adult rats remains approximately constant over a 2-year post-denervation period. At this time, the size of muscle fibers in long-term denervated adult skeletal mus-
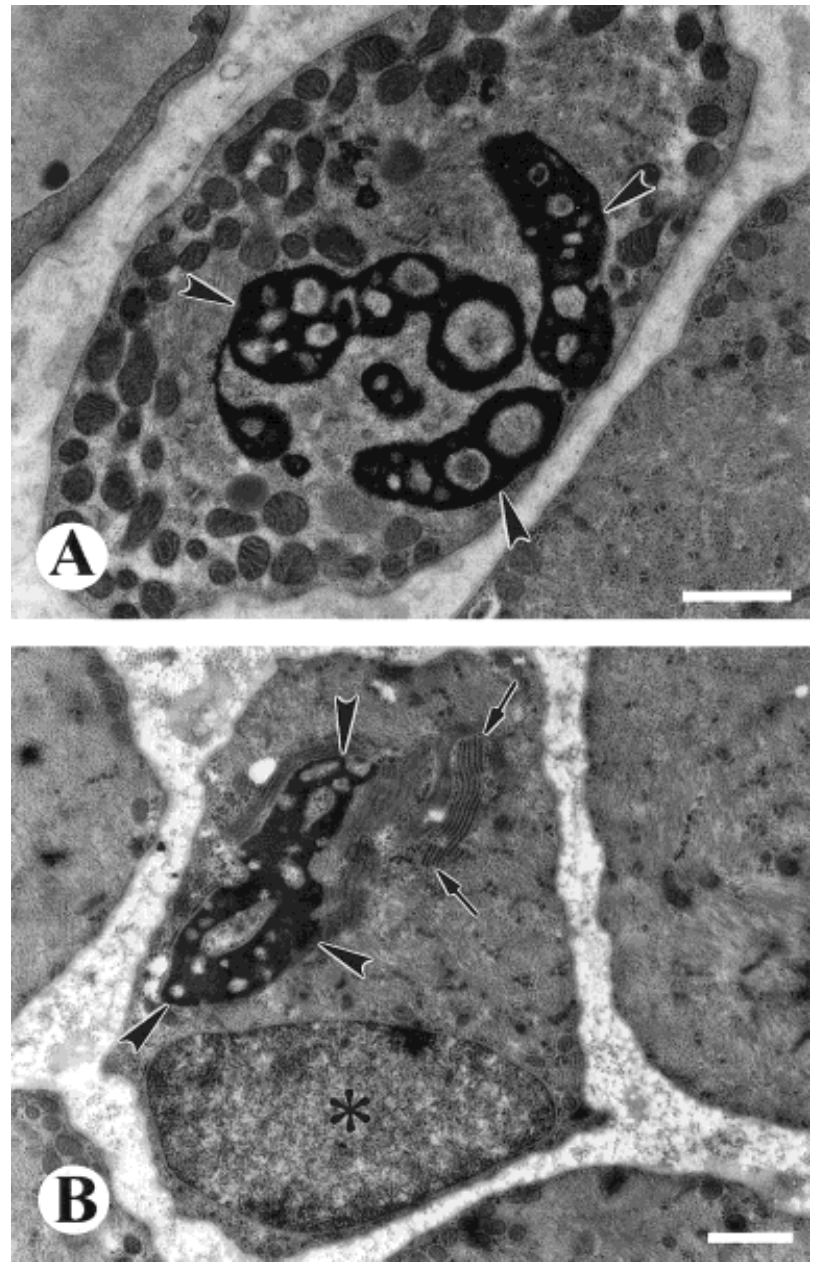

Fig. 6. Electron micrographs showing myonuclear death in muscle fibers from a 25-month denervated EDL muscle. A: Typical picture of nuclear death (arrowheads) in what is probably a newly formed muscle fiber. The fragmentation of a centrally located myonucleus displays a late stage of nuclear degradation. Scale bar $=1 \mu \mathrm{m}$. B: Degenerated (arrowheads) and intact (asterisk) nuclei are simultaneously existing in a persisting muscle fiber. Note that the lamellar structures are only associated with a degenerated myonucleus (arrows). Scale bar $=1 \mu \mathrm{m}$.

Fig. 7. Immunofluorescent photomicrographs showing 25-month denervated and 29-month-old control TA muscles examined for fast and slow myosin expression. After prolonged denervation, the differentiation of Type II and Type I fibers in TA muscle is preserved, although the incidence of Type I muscle fibers is very rare. A: Muscle fibers reacted with an antibody specific for fast-type myosin have variety of sizes, ranging from large (asterisks) to very small (arrows). Scale bar $=25 \mu \mathrm{m}$. B: Single muscle fiber reacted with an antibody specific for slow-type myosin (asterisk). Scale bar $=25 \mu \mathrm{m}$. C: Laminin staining for A. D: Laminin staining for B. E: Long-term denervated TA muscle stained with an antibody for fast-type myosin shows presence of a pure population of Type II muscle fibers in a fascicle (arrowheads). Scale bar $=25 \mu \mathrm{m}$. F: Age-matched control TA muscle stained for slow-type myosin, showing the presence of slow fiber-type grouping (asterisks) in the fascicle. Scale bar $=25 \mu \mathrm{m}$. G: Laminin staining for E. H: Laminin staining for F. 

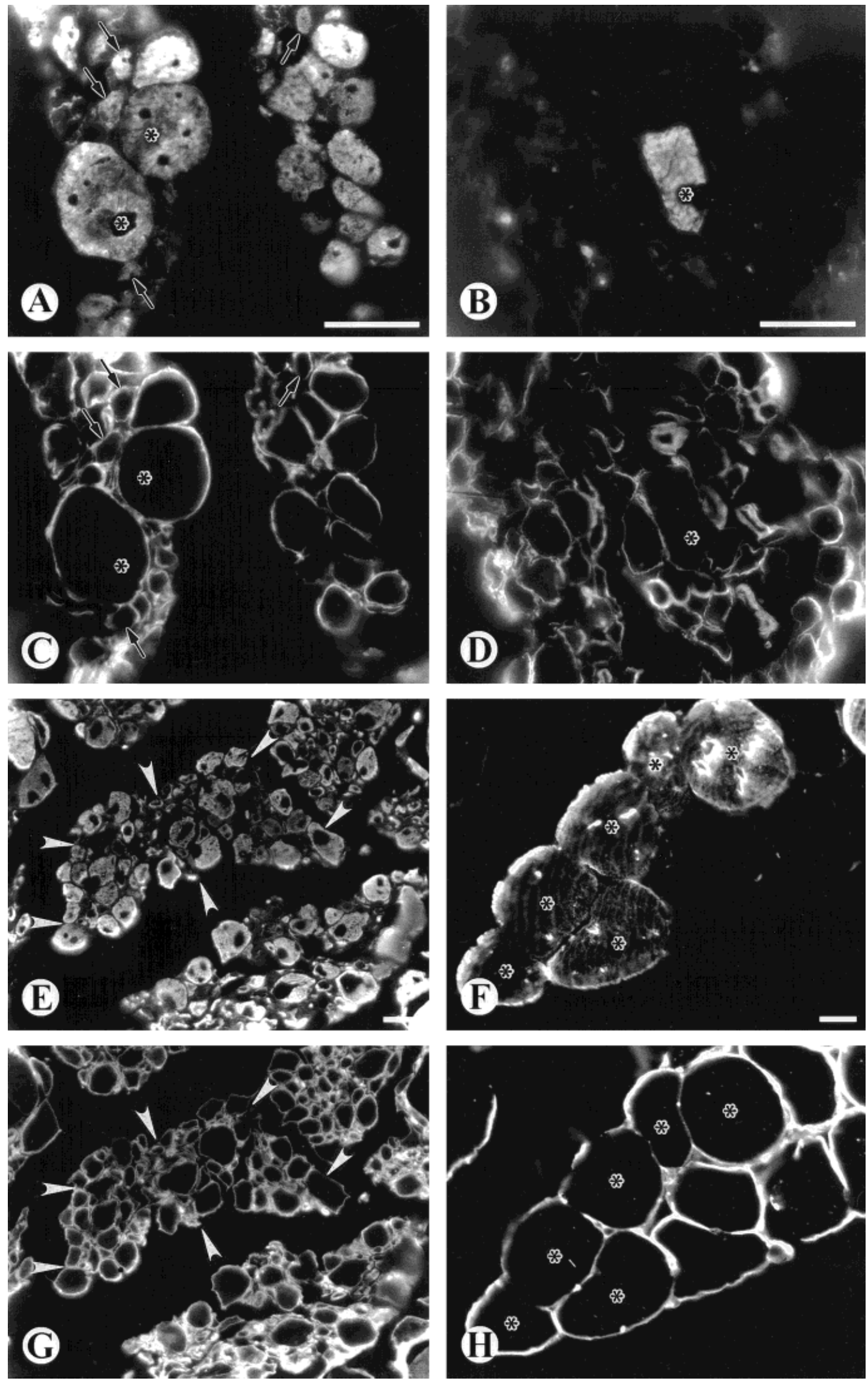

Figure 7. 
cles resembles that characteristic for aneurally developed myotubes in EDL muscles of the rat fetuses at E17 (Condon et al., 1990) or myofibers in soleus muscles of newborn rats that had been denervated at birth (Schmalbruch, 1990). These observations support the possibility that a

A

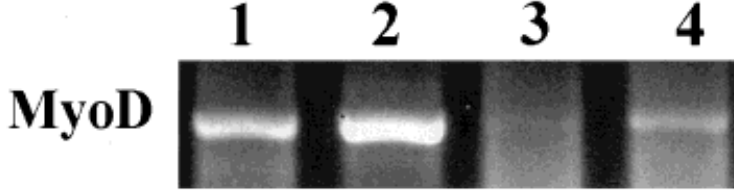

Myogenin

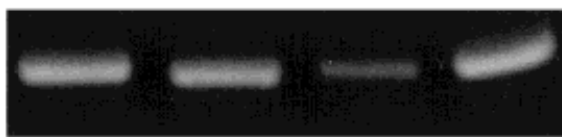

$\alpha-\mathbf{A C h R}$

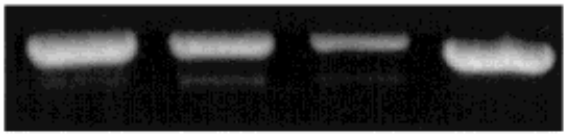

$\varepsilon-\mathbf{A C h R}$

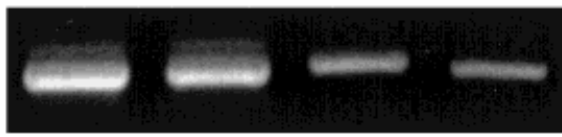

$\gamma-\mathbf{A C h R}$

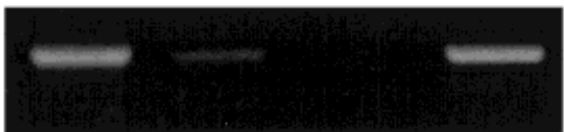

MCK

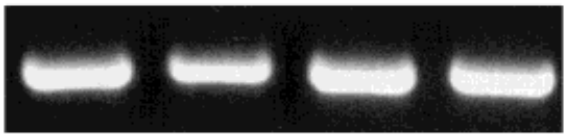

GAPDH

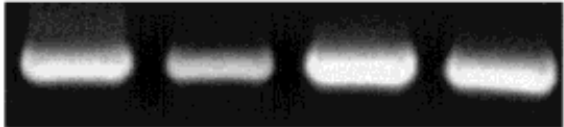

B

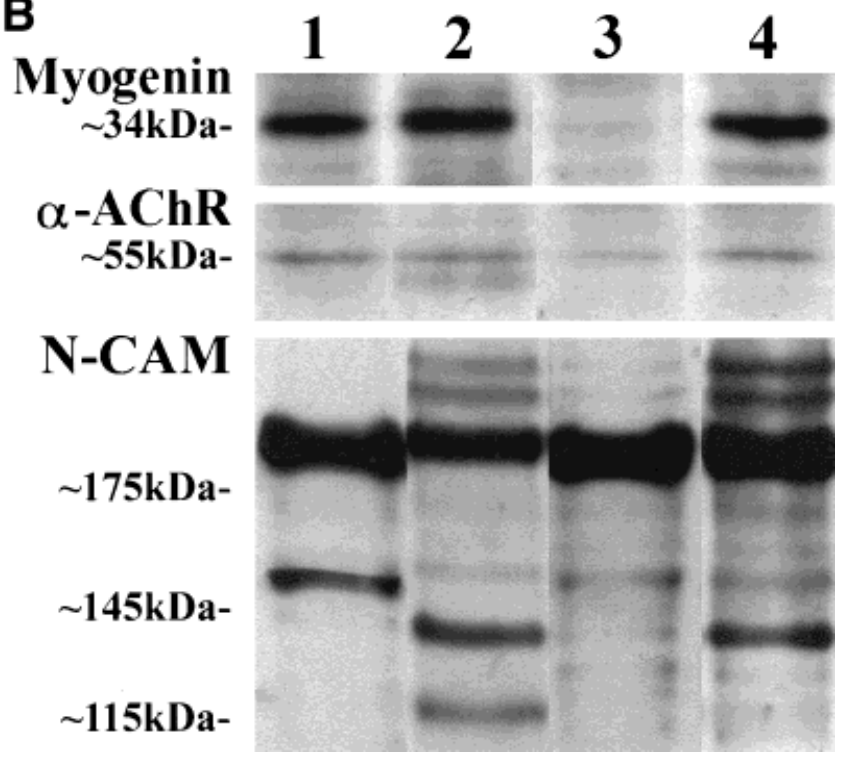

high number of the surviving muscle fibers in extremely long-term denervated muscles consists of a population of newly formed muscle fibers and immature myotube-like structures.

Despite the fact that a majority of surviving muscle fibers in long-term denervated EDL muscles has lost a significant amount of cytoplasm and intracytoplasmic organelles, some of them still reveal certain characteristics of a mature muscle cell. For example, data from our study showed that after prolonged denervation the persisting muscle fibers exhibit peripherally located nuclei and myofilaments organized into sarcomere-like structures (Fig. 1D). The positive reactions of long-term denervated fibers in the TA muscle with antibodies against fast- and slowtype myosin also demonstrated that even after a more than 2-year interruption of the nerve supply, the two distinct types of myosin continue to be detected. In spite of the fact that denervated muscle fibers preferentially express fast-type myosin, solitary slow-type fibers are still present. This finding suggests that in 25-month denervated TA muscles there are at least two separate populations of muscle fibers whose type of myosin expression is independent of the nerve supply. Previous data have shown that fast- and slow-type muscle fibers could be found in aneurally developed hindlimb musculature of rat fetuses (Condon et al., 1990) as well as in rat hindlimb muscles 3 weeks after denervation at birth (Dhoot and Perry, 1983). It has been suggested that fiber types in hindlimb muscles of neonatal rats can develop in the absence of the nervous system (Condon et al., 1990). Our findings suggest that a genetic program regulating myosin expression within the muscle fibers, which was activated early in the rat embryogenesis, continues to be expressed even after a very long period of absence of regulatory influences from the motor neurons. Furthermore, the type-grouping of slow muscle fibers, which always characterizes the fast hindlimb muscles of aged rats (Caccia et al., 1979), does not appear in aged 25-month denervated TA muscles. This is additional evidence that the typegrouping in old skeletal muscles is a sign indicative of denervation and reinnervation processes, occurring entirely under the control of the nervous system (Larsson, 1982).

According to our ultrastructural study, the sites of former neuromuscular junctions on the surface of persist-

Fig. 8. Analysis of 25-month denervated gastrocnemius muscles showing the expression of several developmentally and functionally important muscle-specific proteins at both the RNA and/or protein levels. A: RT-PCR analysis showing the presence of RNA expression of myogenic transcription factors (MyoD and myogenin) and $\alpha-, \epsilon-, \gamma$-subunuts of the nAChR in 25-month denervated muscles. Lane 1: control muscle of 29-month-old rat. Lane 2: 25-month denervated muscle of 29-month-old rat. Lane 3: control muscle of 5-month-old rat. Lane 4: 1-month denervated muscle of 5-month-old rat. To control for equal amounts of input, primers specific to the GAPDH and MCK were used. Note that all types of tested mRNAs are present in long-term denervated muscles. Representative RT-PCR analyses are shown. B: Western blot analysis showing expression of myogenin, $\alpha$-subunit of $\mathrm{nAChR}$ and $\mathrm{N}-\mathrm{CAM}$ in 25-month denervated muscles. Lane 1: control muscle of 29-month-old rat. Lane 2: 25-month denervated muscle of 29-monthold rat. Lane 3: control muscle of 5-month-old rat. Lane 4: 1-month denervated muscle of 5-month-old rat. Note that myogenin, $\alpha$-subunit of the $\mathrm{nAChR}$ and N-CAM proteins, are present in long-term denervated muscles. Representative blots are shown. 

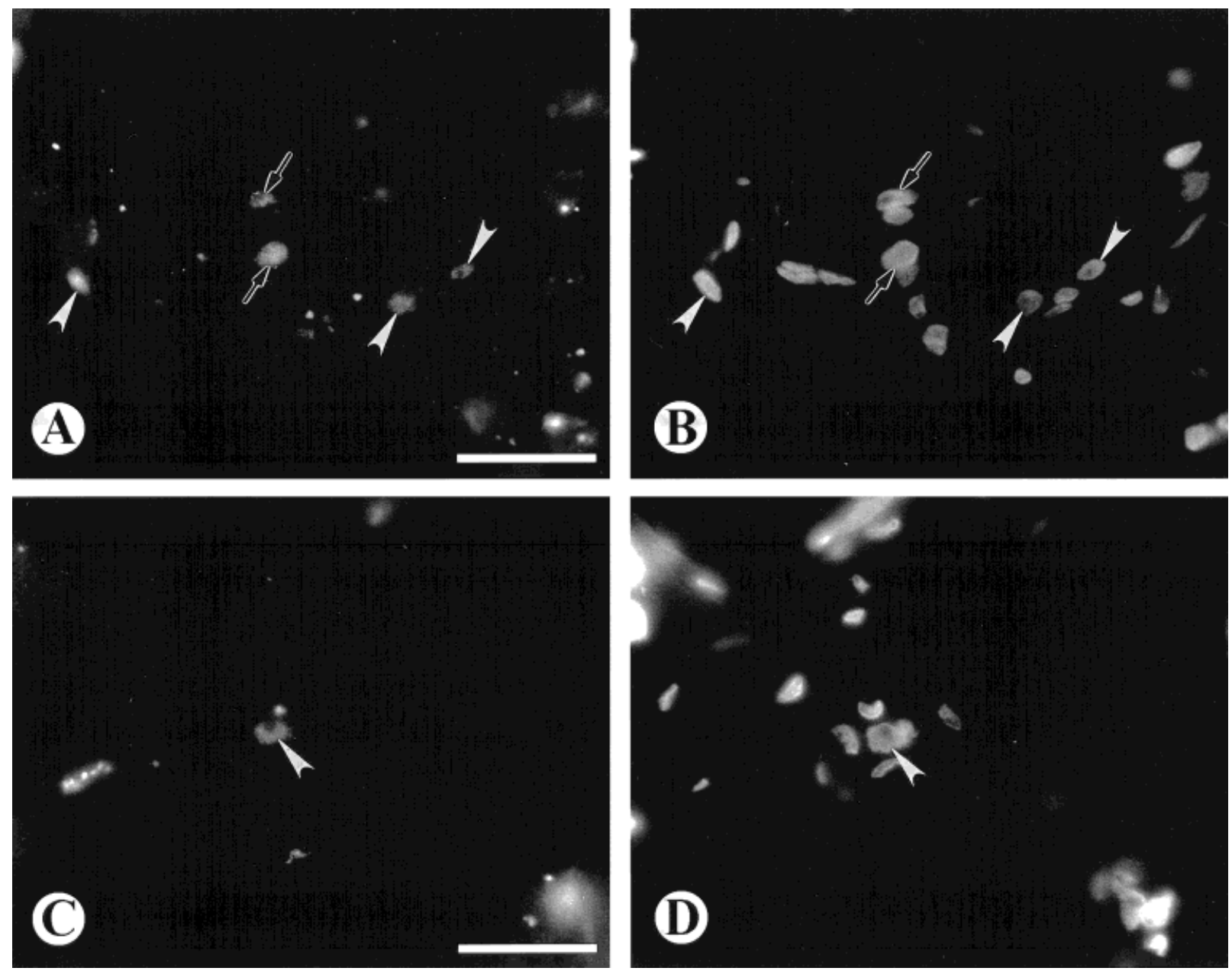

Fig. 9. Immunofluorescent photomicrographs showing the expression of myogenic transcription factors (MyoD and myogenin) in myonuclei of 25-month denervated TA muscles. Note that MyoD-positive myonuclei are more prevalent than myogenin-stained myonuclei. A: Staining of myonuclei with an antibody specific to MyoD in persisting muscle fibers (arrows) and in newly formed muscle fibers (arrowheads). Note that in persisting muscle fibers, among associated nuclei, just one is

positive for MyoD (arrows). Scale bar $=25 \mu \mathrm{m}$. B: Nuclei staining with DAPI for A. C: Staining of myonuclei with an antibody specific to myogenin (arrowhead). Note that only a centrally located nucleus in newly formed fiber is positive for myogenin. Scale bar $=25 \mu \mathrm{m}$. D: Nuclei staining with DAPI for $\mathrm{C}$. Note that the arrowheads and arrows in $\mathrm{B}$ and arrowhead in $D$ point to the same nuclei as in $A$ and $C$, respectively.

ing muscle fibers were readily recognizable despite the prolonged period of denervation. However, the morphology of the post-synaptic apparatus was significantly altered. It was shown earlier that the sites of former endplates could be detected in surviving skeletal muscle fibers even after 17 months of denervation (Sunderland and Ray, 1950). Our data have extended the time of preservation of former end-plate sites on the surface of atrophic muscle fibers to $\sim 2$-years of muscle denervation. Nevertheless, it is very difficult to assess the functional condition of those long-term denervated sites of former neuromuscular junctions with respect to their capacity to accept growing axons if re-innervation were to occur.

In our study, we have found that $\sim 55 \%$ of the examined fiber profiles in 25-month denervated EDL muscle were non-nucleated (Table 1 ). The low $\mathrm{Mn} / \mathrm{F}$ ratio in long-term denervated skeletal muscles of rat hindlimbs is consistent with data reported in previous studies for EDL (Viguie et al., 1997) as well as for soleus muscles (Schmalbruch and

Lewis, 2000). The percentage of non-nucleated muscle fiber profiles presented earlier by Viguie et al. (1997) in 18-month denervated EDL muscles was $\sim 54.8 \%$. Our finding is not unexpected in view of the occurrence of nuclear death within denervated muscle fibers, which has been well described by others (Borisov and Carlson, 2000; $\mathrm{Lu}$ et al., 1997; Rodrigues and Schmalbruch, 1995). An important issue is that severely atrophic muscle fibers in EDL muscles of rats are able to maintain a dynamic balance in the number of myonuclei for months in spite of the extremely prolonged period of denervation.

In order to define the functional status of the genetic program of myogenic differentiation in long-term denervated muscles we analyzed the expression of some developmentally and functionally important muscle-specific proteins at both the RNA and/or protein levels. It was previously shown that increased expression of MyoD, myogenin, and nAChR occurs early after muscle denervation in rats (Witzemann et al., 1987; Weis, 1994) and 

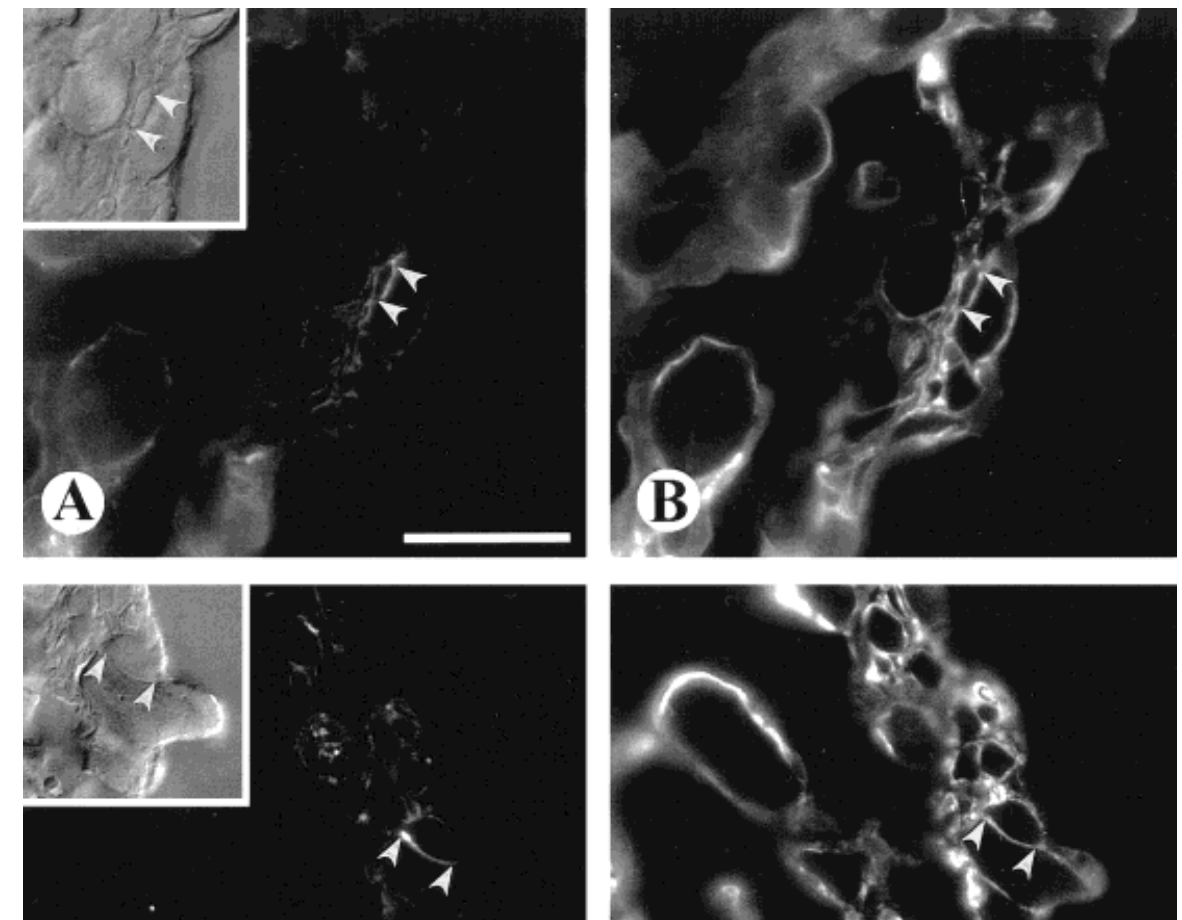

C
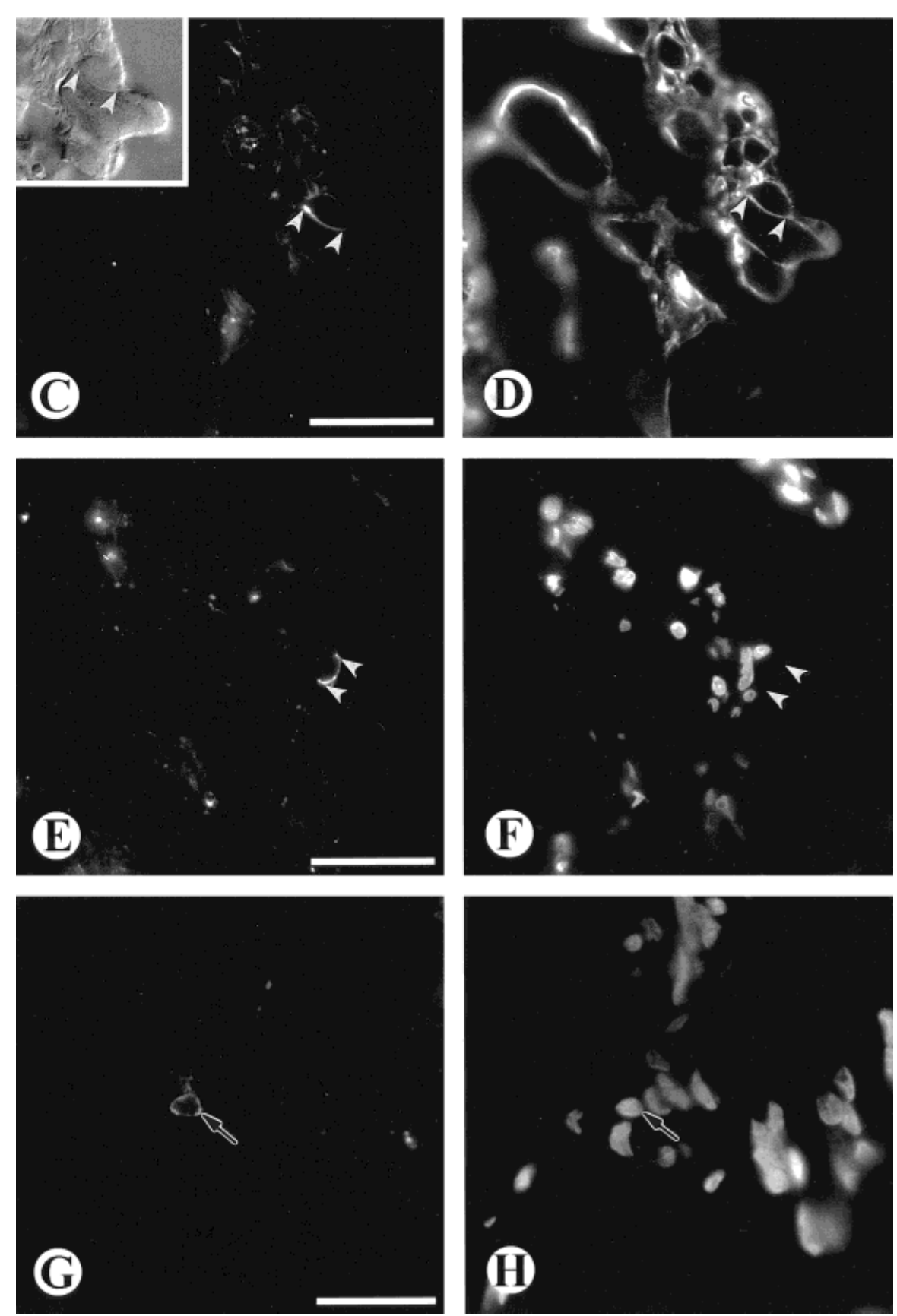

Figure 10 
continues to be detected in chronically denervated skeletal muscle up to 7 months (Adams et al., 1995). Our study conducted on 25-month denervated skeletal muscles shows that myogenic transcription factors $(\mathrm{MyoD}$ and myogenin) as well as the embryonic $\gamma$-subunit of the nAChR are expressed in severely atrophic muscles at the mRNA and/or proteins levels. Additionally, according to our immunocytochemical studies of 25-month denervated TA muscles, MyoD and myogenin proteins were detected in myonuclei of both newly formed and persisting muscle fibers. Thus, our data show that the genetic program of myogenic differentiation continues to be activated in surviving muscle fibers of 25-month denervated skeletal muscles of the rat hindlimb.

The increased levels for MyoD, myogenin, and embryonic $\gamma$-subunit of the nAChR in 29-month-old control skeletal muscles (Fig. 8) compared to control muscles of 5 -month-old rats is in agreement with previously published results (Gomes and Booth, 1998; Kostrominova et al., 2000; Musaro et al., 1995). This phenomenon could be explained by aging-related denervation/reinnervation of skeletal muscle fibers that occurs in old age (Caccia et al., 1979; Larsson, 1982).

In our study, we also have used immunofluorescence and immunoblotting methods to determine the presence and distribution of N-CAM protein expression in very long-term denervated rat skeletal muscles. Previously, Covault and Sanes $(1985,1986)$ showed that N-CAM accumulates mostly on the surface of embryonic myoblasts and myotubes as well as on the surface of denervated or paralyzed adult muscle fibers and satellite cells, but it is absent from the surface of normally innervated adult muscle fibers. They suggested that N-CAM plays an important role in the regulation of muscle's receptivity to innervation as well as during the process of myogenesis. In our study, we have found that a few distinct N-CAM isoforms are also present in 25-month denervated skeletal muscles (Fig. 8B, lane 2). Moreover, N-CAM positive staining in long-term denervated TA muscles was observed in the attachment areas between satellite cells or myotube-like structures and their associated persisting muscle fibers. From the study of Covault and Sanes (1986), it is well known that during rat embryonic myogenesis N-CAM is highly concentrated on the surface of myoblasts before fusion and on the surface of newly formed myotubes, as well as in areas of contact between adjacent myotubes. From this point of view, sites with marked N-CAM expression observed in 25-month denervated skeletal muscles

Fig. 10. Immunofluorescent photomicrographs showing the distribution of N-CAM expression in a 25-month denervated TA muscles. A: $\mathrm{N}$-CAM specific labeling detected in the attachment area between a satellite cell and its associated muscle fiber (arrowheads). Inset: Attachment area in differential interference contrast (DIC). Scale bar $=32 \mu \mathrm{m}$. B: Laminin staining for A. C: N-CAM expression located in the area of contact between a myotube-like structure and its associated muscle fiber (arrowheads). Inset: Area of contact in DIC. Scale bar $=32 \mu \mathrm{m}$. D: Laminin staining for C. E: N-CAM expression on the free surface of a persisting muscle fiber (arrowheads). Scale bar $=32 \mu \mathrm{m}$. F: Nuclei staining with DAPI for E. G: Newly formed muscle fiber with a centrally located nucleus shows N-CAM expression on its entire surface (arrow). Scale bar $=32 \mu \mathrm{m}$. H: Nuclei staining with DAPI for G. Note that the arrowheads in $\mathrm{B}, \mathrm{D}, \mathrm{F}$, and the arrow in $\mathrm{H}$ point to the same nuclei as in $A, C, E$, and $G$, respectively. might represent areas of ongoing reparative myogenesis. On the contrary, the N-CAM positive staining of the majority of very long-term denervated persisting muscle fibers was significantly weaker.

Several lines of evidence indicate that continuing myogenesis is a prominent part of the structural changes occurring in long-term denervated muscles ( $\mathrm{Lu}$ et al., 1997; Rodrigues and Schmalbruch, 1995; Schmalbruch et al., 1991). In our study, the observation of activated satellite cells as well as newly formed muscle fibers, showing different stages of maturation, also confirms that a process of reparative myogenesis take places in skeletal muscles 25 months after denervation. The fact that some of the regenerated muscle fibers are covered by folded basal laminae and a few myotubes have a common basal lamina suggests that they were formed from surviving satellite cells inside the preexisting basal lamina tubes left after the death of original muscle fibers. At the same time, the myotubes located in groove-like channels on the surface of persisting muscle fibers showing unfolded de novo-formed basal lamina probably represent the process of the new fiber development without the degeneration of original muscle fiber.

New fiber formation occurred despite the fact that 25month denervated EDL muscles contain a significantly smaller number of satellite cells than that found in agematched control EDL muscles (Table 1). Interestingly, the number of satellite cells in 25-month denervated EDL muscles was quite different, depending on which method of calculation was used. The number of satellite cells expressed as a percentage of total nuclei counted beneath the basement membrane on fiber cross-sections was $\sim 0.51 \%$, whereas the value expressed as the ratio of the number of satellite cell cross-sections to the number of fiber cross-sections calculated in same muscle fascicles was $\sim 0.23 \%$. For 29 -month-old control EDL muscles, those values were $\sim 1.42$ and $1.5 \%$, respectively. The significant difference of the mean number of satellite cells calculated in 25-month denervated EDL muscles, compared to control muscles, could reasonably be explained by the elevated number of non-nucleated muscle fiber crosssections ( $\sim 55 \%)$ and progressive nuclear elimination. Previously, it was shown that the number of satellite cells in normal EDL muscles expressed as a proportion of satellite cell nuclei to myofiber nuclei decreased with aging and was calculated as $\sim 1.9 \%$ in 24-month-old rats (Gibson and Schultz, 1983). In a recent study, Viguie et al. (1997) reported that 18-month denervated EDL muscles contained $\sim 1.1 \%$ satellite cells. Our results are consistent with the data of these authors, which showed that a progressive decrease in the number of satellite cells occurred in normally aged EDL muscles and during long-term denervation. Nevertheless, it is difficult to explain why satellite cells vanish from or are greatly diminished in skeletal muscle in both extremely aged and very long-term denervated skeletal muscles. Previously, Mussini et al. (1987) observed that in the permanently denervated soleus muscle of 2-3-month-old rats, repeated bupivacaine treatment every time could evoke a new phase of muscle fiber regeneration and preserve the number of satellite cells at a high level. Moreover, they also found that spontaneous myogenesis continued to occur at a low rate in the regenerated long-term denervated soleus muscle of adult rats. On the other hand, EDL and soleus muscles of newborn rats denervated at birth contained only atrophic 

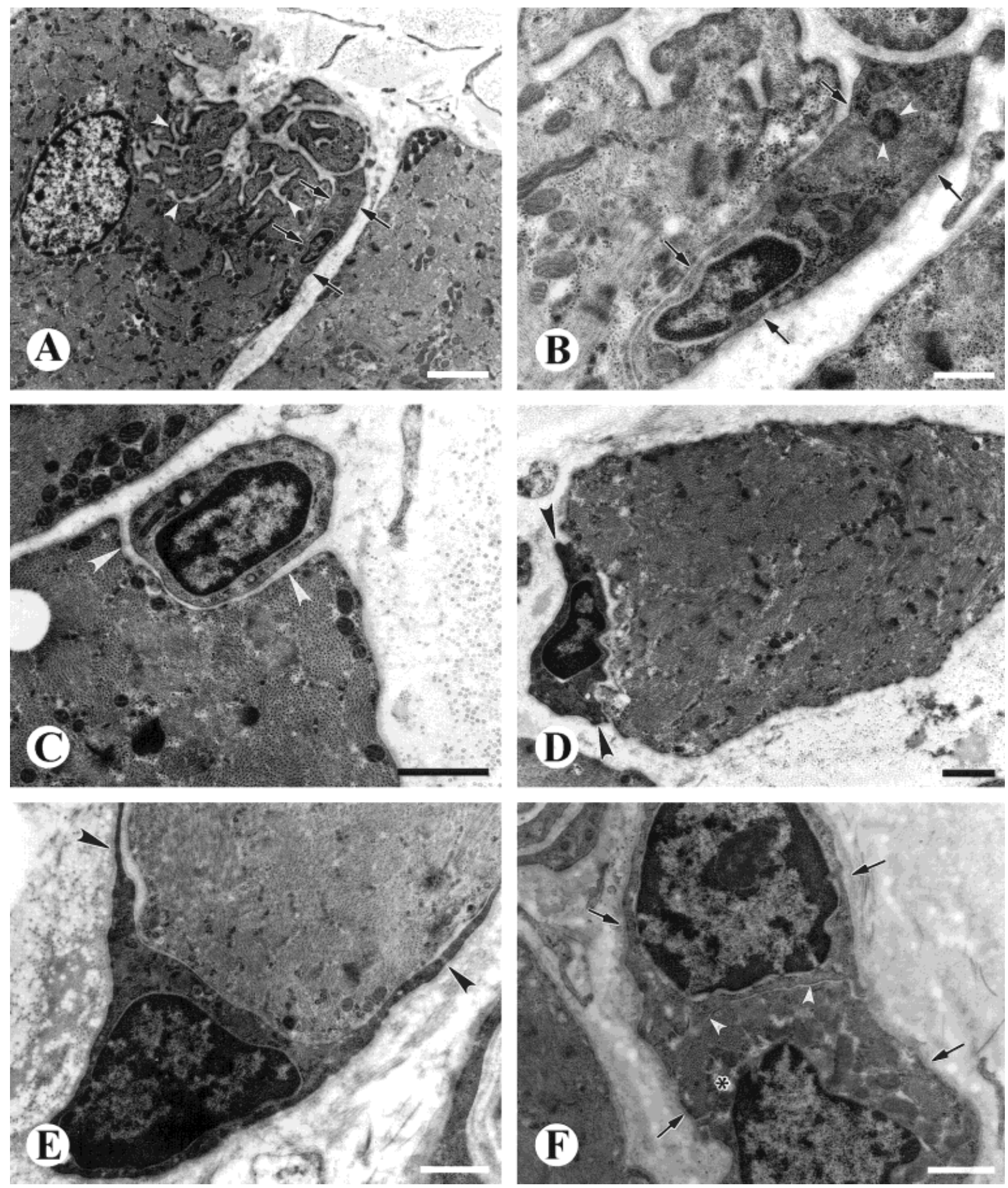

Fig. 11. Electron micrographs of 25-month denervated EDL muscles showing satellite cells in different stages of activation. A: An activated satellite cell (arrows) attached to a muscle fiber close to the area of a former motor end-plate (arrowheads). Scale bar $=2 \mu \mathrm{m}$. B: High magnification of the satellite cell (arrows) shown in A. Note the presence of a centriole in the cytoplasm (arrowheads). Scale bar $=0.5 \mu \mathrm{m}$. C: Satellite cell located in a groove-like channel on the surface of an associated muscle fiber. Note the wide gap between the satellite cell and the muscle fiber filled by the basal lamina material separating them from each other

(arrowheads). Scale bar $=1 \mu \mathrm{m}$. D: An activated satellite cell beginning to form cytoplasmic processes (arrowheads). Scale bar $=1 \mu \mathrm{m}$. E: Long cytoplasmic extensions (arrowheads) formed by a growing satellite cell surrounding an atrophic muscle fiber. Scale bar $=1 \mu \mathrm{m}$. F: Two myotube-like fibers surrounded by a common basal lamina (arrows) and separated from each other by a thin gap space (arrowheads). Note the presence of organized contractile filaments in the cytoplasm of one of them (asterisk). Scale bar $=1 \mu \mathrm{m}$. 


\section{Original fiber}

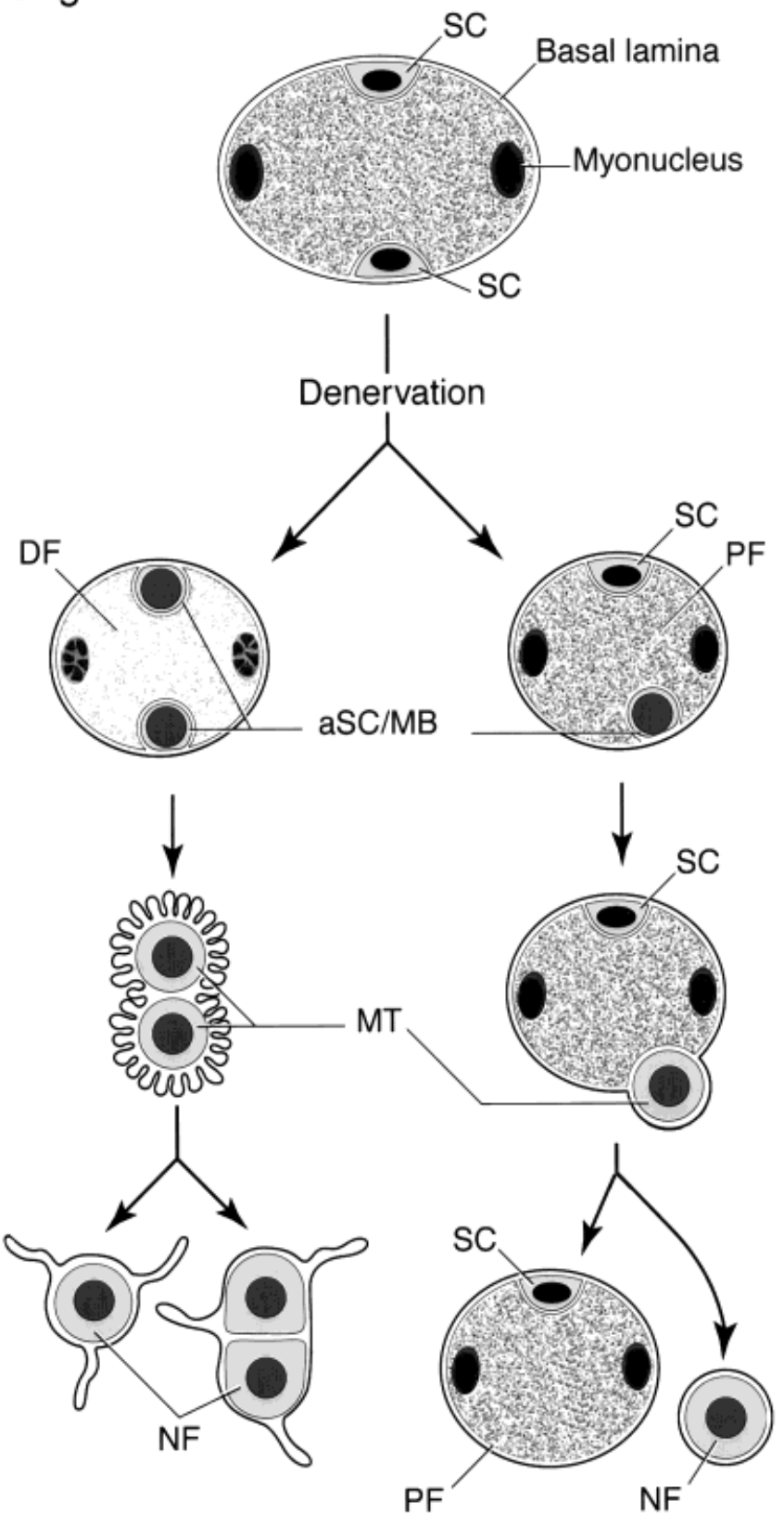

Fig. 12. Schematic representation of a hypothetical mechanism that outlines the attenuation of the satellite cell population during long-term denervation of rat hindlimb skeletal muscles. After prolonged axotomy, the entire population of the original muscle fibers associated with quiescent satellite cells (SC) undergoes two major changes: persistence and/or degeneration. Concurrently, the processes of satellite cell activation (aSC), myoblast (MB) growth, and myotube (MT) formation take place in both degenerating (DF) and persisting (PF) muscle fibers. With time, the death of persisting (original) muscle fibers and continuous neomyogenesis lead to the substitution of original muscle tissue by a population of immature newly formed (NF) fibers that are not associated with satellite cells. myotube-like fibers, whereas satellite cells were practically lacking in both muscles (Rodrigues and Schmalbruch, 1995; Schmalbruch, 1990). Based on the findings obtained in 25-month denervated EDL and TA muscles, we agree with the observations made by Schmalbruch and Lewis (1994) in soleus muscles that long-term denervated skeletal muscles morphologically resemble aneural muscle regenerates, populated by a high number of immature newly formed muscle fibers. However, in 25-month denervated skeletal muscles, we have also found a population of relatively large persisting muscle fibers associated with satellite cells, whereas we have never seen satellite cells attached to the surface of newly formed muscle fibers. Recently, Schmalbruch and Lewis (2000) presented additional data supporting the idea that exhaustion of satellite cells in denervated rat skeletal muscles was predominantly due to repeated cycles of muscle fiber degeneration and regeneration, when active satellite cells constantly fused in myotubes or incorporated into original muscle fibers. Based on our results, we hypothesize that the attenuation of the satellite cell population in 25-month denervated skeletal muscles could be due to two facts: 1 .) elimination of persisting (original) muscle fibers, the only ones associated with satellite cells, and 2.) increasing number of immature newly formed myotubes/fibers, which we did not find to be associated with satellite cells (Fig. 12).

In conclusion, our study showed that within the overall tendency to gross atrophy and degeneration in 25-month denervated skeletal muscles of rat hindlimbs simultaneous processes of muscle tissue regeneration also occur. Nevertheless, we suggest that the progressive death of persisting muscle fibers, continuous reparative myogenesis, and consecutive substitution of the original muscle tissue by a population of immature newly formed fibers could lead to a significant reduction in the number of satellite cells in long-term denervated muscles. In connection with other factors, such as fibrosis (Gutmann and Zelená, 1962), significant deterioration of nerve sheaths (Fu and Gordon, 1995), and loss of capillary supply (Borisov et al., 2000), it could considerably reduce the capacity of a long-term denervated muscle to become restored either by reinnervation or by regeneration (Carlson and Faulkner, 1988; Carlson et al., 1996; Gulati, 1988; Irintchev et al., 1990).

\section{ACKNOWLEDGMENTS}

We are grateful to Dr. Daniel Goldman for allowing us to use equipment in his laboratory.

\section{LITERATURE CITED}

Adams L, Carlson BM, Henderson L, Goldman D. 1995. Adaptation of nicotinic acetylcholine receptor, myogenin, and MRF4 gene expression to long-term muscle denervation. J Cell Biol 131:1341-1349.

Anzil AP, Wernig A. 1989. Muscle fibre loss and reinnervation after long-term denervation. J Neurocytol 18:833-845.

Bittner RE, Czernizky W, Shorny S, Schaden G, Hauser E, Hoger H. 1995. Denervation increases the number of muscle fibers in normal and dystrophic mdx mice. In: Frey M,

Giovanoli P, editor. Proceedings of the 4th International Muscle Symposium. Zurich: Universitatspital. p 67-68.

Borisov AB, Carlson BM. 2000. Cell death in denervated skeletal muscle is distinct from classical apoptosis. Anat Rec 258:305-318.

Borisov AB, Huang SK, Carlson BM. 2000. Remodeling of the vascular bed and progressive loss of capillaries in denervated skeletal muscle. Anat Rec 258:292-304. 
Carlson BM, Faulkner JA. 1988. Reinnervation of long-term denervated rat muscle freely grafted into an innervated limb. Exp Neurol 102:50-56.

Carlson BM, Billington L, Faulkner JA. 1996. Studies on the regenerative recovery of long-term denervated muscle in rats. Restor Neurol Neurosci 10:77-84.

Caccia MR, Harris JB, Johnson MA. 1979. Morphology and physiology of skeletal muscle in aging rodents. Muscle Nerve 2:202-212.

Condon K, Silberstein L, Blau HM, Thompson WJ. 1990. Differentiation of fiber types in aneural musculature of the prenatal rat hindlimb. Dev Biol 138:275-295.

Covault J, Sanes J. 1985. Neural cell adhesion molecule (N-CAM) accumulates in denervated and paralyzed skeletal muscles. Proc Natl Acad Sci USA 82:4544-4548.

Covault J, Sanes J. 1986. Distribution of N-CAM in synaptic and extrasynaptic portions of developing and adult skeletal muscle. J Cell Biol 1986:716-730.

Dhoot GK, Perry SV. 1983. Effect of denervation at birth on the development of skeletal muscle cell types in the rat. Exp Neurol 82:131-142.

Eftimie R, Brenner HR, Buonanno A. 1991. Myogenin and MyoD join a family of skeletal muscle genes regulated by electrical activity. Proc Natl Acad Sci USA 88:1349-1353.

Fu SY, Gordon T. 1995. Contributing factors to poor functional recovery after delayed nerve repair: prolonged denervation. J Neurosci 15:3886-3895.

Gibson MC, Schultz E. 1983. Age-related differences in absolute numbers of skeletal muscle satellite cells. Muscle Nerve 6:574-580.

Gomes RR, Jr, Booth FW. 1998. Expression of acetylcholine receptor mRNAs in atrophying and nonatrophying skeletal muscles of old rats. J Appl Physiol 85:1903-1908.

Gulati AK. 1988. Long-term retention of regenerative capability after denervation of skeletal muscle, and dependency of late differentiation on innervation. Anat Rec 220:429-434.

Gulati AK. 1990. Restoration of denervated skeletal muscle transplants after reinnervation in rats. Restor Neurol Neurosci 2:23-29.

Gutmann E. 1948. Effect of delay of innervation on recovery of muscle after nerve lesions. J Neurophysiol 11:279-294.

Gutmann E. 1962. The denervated muscle. Prague: Publishing House of the Czechoslovak Academy of Sciences.

Gutmann E, Young JZ. 1944. The re-innervation of muscle after various periods of atrophy. J Anat 78:15-44.

Gutmann E, Zelená J. 1962. Morphological changes in the denervated muscle. In: Gutmann E, editor. The denervated muscle. Prague: Publishing House of the Czechoslovak Academy of Sciences. p 57102.

Horton RM, Manfredi AA, Conti-Tronconi BM. 1993. The 'embryonic' gamma subunit of the nicotinic acetylcholine receptor is expressed in adult extraocular muscle. Neurology 43:983-986.

Irintchev A, Draguhn A, Wernig A. 1990. Reinnervation and recovery of mouse soleus muscle after long-term denervation. Neuroscience 39:231-243.

Kraus B, Pette D. 1997. Quantification of MyoD, myogenin, MRF4 and Id- 1 by reverse-transcriptase polymerase chain reaction in rat muscles. Effect of hypothyroidism and chronic low-frequency stimulation. Eur J Biochem 247:98-106.

Kostrominova TY, Macpherson PCD, Carlson BM, Goldman D. 2000. Regulation of myogenin protein expression in denervated muscles from young and old rats. Am J Physiol Regulatory Integrative Comp Physiol 279:R179-R188.
Larsson L. 1982. Aging in mammalian skeletal muscle. In: Mortimer JA, Pirozzolo FJ, Maletta GJ, editors. The aging motor system. New York: Praeger. p 60-97.

Lu D-X, Huang S-K, Carlson BM. 1997. Electron microscopic study of long-term denervated rat skeletal muscle. Anat Rec 248:355-365.

Merlie JP, Mudd J, Cheng T-C, Olson EN. 1994. Myogenin and acetylcholine receptor a gene promoters mediate transcriptional regulation in response to motor innervation. J Biol Chem 269:24612467.

Moore SE, Walsh FS. 1986. Nerve dependent regulation of neuronal cell adhesion molecule expression in skeletal muscle. Neuroscience 18:499-505.

Musaro A, Cusella De Angelis MG, Germani A, Ciccarelli C, Molinaro M, Zani BM. 1995. Enhanced expression of myogenic regulatory genes in aging skeletal muscle. Exp Cell Res 221:241-248.

Mussini I, Favaro G, Carraro U. 1987. Maturation, dystrophic changes and the continuous production of fibres in skeletal muscle regenerating in the absence of nerve. J Neuropathol Exp Neurol 46:315-331.

Rodrigues A de C, Schmalbruch H. 1995. Satellite cells and myonuclei in long-term denervated rat muscles. Anat Rec 243:430-437.

Sanes JR, Schachner M, Covault J. 1986. Expression of several adhesive macromolecules (N-CAM, L1, J1, NILE, uvomorulin, laminin, fibronectin, and a heparan sulfate proteoglycan) in embryonic, adult, and denervated adult skeletal muscle. J Cell Biol 102:420431.

Schmalbruch H. 1987. Loss of sensory neurons after sciatic nerve section in the rat. Anat Rec 219:323-329.

Schmalbruch H. 1988. The effect of peripheral nerve injury on immature motor and sensory neurons and on muscle fibers. Possible relation to the histogenesis of Werdnig-Hoffmann disease. Rev Neurol 144:721-729.

Schmalbruch H. 1990. Growth and denervation response of skeletal muscle fibers of newborn rats. Muscle Nerve 13:421-432.

Schmalbruch H, Lewis DM. 1994. A comparison of the morphology of denervated and aneurally regenerated soleus muscle of rat. J Muscle Res Cell Motil 15:256-266.

Schmalbruch H, Lewis DM. 2000. Dynamics of nuclei of muscle fibers and connective tissue cells in normal and degenerated rat muscles. Muscle Nerve 23:617-626.

Schmalbruch H, Al-Amood WS, Lewis DM. 1991. Morphology of longterm denervated rat soleus muscle and the effect of chronic electrical stimulation. J Physiol (Lond.) 441:233-241.

Soileau LC, Silberstein L, Blau HM, Thompson WJ. 1987. Reinnervation of muscle fiber types in the newborn rat soleus. J Neurosci 7:4176-41194

Sunderland S, Ray LJ. 1950. Denervation changes in mammalian striated muscle. J Neurol Neurosurg Psychiatry 13:159-177.

Trachtenberg JT. 1998. Fiber apoptosis in developing rat muscles is regulated by activity, neuregulin. Dev Biol 196:193-203.

Viguie CA, Lu D-X, Huang S-K, Rengen H, Carlson BM. 1997. Quantitative study of the effects of long-term denervation on the extensor digitorum longus muscle of the rat. Anat Rec 248:346-354.

Walsh FS, Moore SE. 1985. Expression of cell adhesion molecule, $\mathrm{N}-\mathrm{CAM}$, in diseases of adult human skeletal muscle. Neurosci Lett 59:73-78.

Weis J. 1994. Jun, Fos, MyoD1 and myogenin proteins are increased in skeletal muscle fiber nuclei after denervation. Acta Neuropathol 87:63-70.

Witzemann V, Barg B, Nishikawa Y, Sakmann B, Numa S. 1987. Differential regulation of muscle acetylcholine receptor $\gamma$ - and $\epsilon$-subunit mRNAs. FEBS Lett 223:104-112. 